\title{
LY-CoV1404 (bebtelovimab) potently neutralizes SARS-CoV-2 variants
}

Kathryn Westendorf ${ }^{1}$, Lingshu Wang ${ }^{2}$, Stefanie Žentelis ${ }^{1}$, Denisa Foster ${ }^{3}$, Peter Vaillancourt ${ }^{3}$, Matthew Wiggin ${ }^{1}$, Erica Lovett ${ }^{1}$, Robin van der Lee ${ }^{1}$, Jörg Hendle ${ }^{3}$, Anna Pustilnik ${ }^{3}$, J. Michael Sauder ${ }^{2}$, Lucas Kraft ${ }^{1}$, Yuri Hwang ${ }^{1}$, Robert W. Siegel ${ }^{4}$, Jinbiao Chen ${ }^{4}$, Beverly A. Heinz ${ }^{4}$, Richard E. Higgs ${ }^{4}$, Nicole Kallewaard ${ }^{4}$, Kevin Jepson ${ }^{1}$, Rodrigo Goya ${ }^{1}$, Maia A. Smith ${ }^{1}$, David W. Collins ${ }^{1}$, Davide Pellacani ${ }^{1}$, Ping Xiang ${ }^{1}$, Valentine de Puyraimond ${ }^{1}$, Marketa Ricicova ${ }^{1}$, Lindsay Devorkin ${ }^{1}$, Caitlin Pritchard ${ }^{1}$, Aoise O’Neill ${ }^{1}$, Kush Dalal ${ }^{1}$, Pankaj Panwar ${ }^{1}$, Harveer Dhupar ${ }^{1}$, Fabian A. Garces $^{1}$, Courtney Cohen ${ }^{5}$, John Dye ${ }^{5}$, Kathleen E. Huie ${ }^{5}$, Catherine V. Badger ${ }^{5}$, Darwyn Kobasa $^{6,7}$, Jonathan Audet ${ }^{6,7}$, Joshua J. Freitas ${ }^{3}$, Saleema Hassanali ${ }^{3}$, Ina Hughes ${ }^{3}$, Luis Munoz ${ }^{3}$, Holly C. Palma ${ }^{3}$, Bharathi Ramamurthy ${ }^{3}$, Robert W. Cross ${ }^{7,8}$, Thomas W. Geisbert ${ }^{7,8}$, Vineet Menacherry $^{8}$, Kumari Lokugamage ${ }^{8}$, Viktoriya Borisevich ${ }^{8}$, Iliana Lanz ${ }^{1}$, Lisa Anderson ${ }^{1}$, Payal Sipahimalani ${ }^{1}$, Kizzmekia S. Corbett ${ }^{2}$, Eun Sung Yang ${ }^{2}$, Yi Zhang ${ }^{2}$, Wei Shi ${ }^{2}$, Tongqing Zhou ${ }^{2}$, Misook Choe' ${ }^{2}$, John Misasi², Peter D. Kwong ${ }^{2}$, Nancy J. Sullivan², Barney S. Graham², Tara L. Fernandez ${ }^{1}$, Carl L. Hansen ${ }^{1}$, Ester Falconer ${ }^{1}$, John R. Mascola ${ }^{2}$, Bryan E. Jones ${ }^{3^{*}}$, and Bryan C. Barnhart $^{1^{*}}$

${ }^{1}$ AbCellera Biologics Inc., Vancouver, BC, Canada

${ }^{2}$ Vaccine Research Center, National Institute of Allergy and Infectious Diseases, National Institutes of Health, Bethesda, MD, USA

${ }^{3}$ Lilly Biotechnology Center, Eli Lilly and Company, San Diego, CA, USA

${ }^{4}$ Eli Lilly and Company, Indianapolis, IN, USA

5 U.S. Army Medical Research Institute of Infectious Diseases (USAMRIID), Frederick, MD, 21702, USA

6 National Microbiology Laboratory, Public Health Agency of Canada, Winnipeg, Manitoba, Canada

${ }^{7}$ University of Manitoba, Winnipeg, Manitoba, Canada

${ }^{8}$ Galveston National Laboratory, University of Texas Medical Branch, Galveston, TX, 77555, USA; Department of Microbiology and Immunology, University of Texas Medical Branch, Galveston, TX, 77555, USA.

${ }^{*}$ Corresponding author

bo.barnhart@abcellera.com

jones bryan edward@lilly.com

In Brief: LY-CoV1404 is a potent SARS-CoV-2-binding antibody that neutralizes all known variants of concern and whose epitope is rarely mutated.

\section{Highlights}

- LY-CoV1404 potently neutralizes SARS-CoV-2 authentic virus and known variants of concern including the B.1.1.529 (Omicron) and B.1.617.2 (Delta) variants

- No loss of potency against currently circulating variants

- Binding epitope on RBD of SARS-CoV-2 is rarely mutated in GISAID database

- Breadth of neutralizing activity and potency supports clinical development 


\section{Abstract}

SARS-CoV-2 neutralizing monoclonal antibodies (mAbs) can reduce the risk of hospitalization when administered early during COVID-19 disease. However, the emergence of variants of concern has negatively impacted the therapeutic use of some authorized mAbs. Using a high throughput B-cell screening pipeline, we isolated a highly potent SARS-CoV-2 spike glycoprotein receptor binding domain (RBD)-specific antibody called LY-CoV1404 (also known as bebtelovimab). LY-CoV1404 potently neutralizes authentic SARS-CoV-2 virus, including the prototype, B.1.1.7, B.1.351 and B.1.617.2). In pseudovirus neutralization studies, LY-CoV1404 retains potent neutralizing activity against numerous variants including B.1.1.7, B.1.351, B.1.617.2, B.1.427/B.1.429, P.1, B.1.526, and B.1.1.529, and retains binding to spike proteins with a variety of underlying RBD mutations including K417N, L452R, E484K, and N501Y. Structural analysis demonstrates that RBD residues comprising the LY-CoV1404 epitope are highly conserved with the exception of N439 and N501. Notably, the binding and neutralizing activity of LY-CoV1404 is unaffected by the most common mutations at these positions (N439K and N501Y). The breadth of reactivity to amino acid substitutions present among current VOC together with broad and potent neutralizing activity and the relatively conserved epitope suggest that LY-CoV1404 has the potential to be an effective therapeutic agent to treat all known variants causing COVID-19.

\section{Introduction}

Variants of SARS-CoV-2 continue to alter the trajectory of the COVID-19 pandemic, which at the time of writing has infected over 271 million people world-wide and is responsible for more than 5.3 million deaths (https://covid19.who.int/). As predicted, SARS-CoV-2 has continued to evolve 
as the pandemic has progressed (Mercatelli and Giorgi, 2020; Pachetti et al., 2020). Selective pressures and viral adaptation during prolonged, suboptimally-treated infections are thought to have generated numerous variants (McCormick et al., 2021), some significantly diminishing the effectiveness of COVID-19 clinical countermeasures (Altmann et al., 2021; Plante et al., 2020). Variants of concern (VOC) represent a closely monitored subset of the many detected SARSCoV-2 variants, due to their potential for increased transmissibility, and ability to evade immunity produced by infection or vaccines while reducing the efficacies of antibody-based treatments (Hoffmann et al., 2021; Kuzmina et al., 2021; McCormick et al., 2021; Thomson et al., 2021; Wang et al., 2021b). The impact of VOC continues to increase (World Health Organization, 2021), with emerging variants threatening to slow the pace and success of global vaccination efforts and limit the effectiveness of existing COVID-19 treatments (Davies et al.; Munnink et al., 2021; Plante et al., 2020; Tegally et al., 2021).

Many studies have demonstrated the clinical safety and efficacy of antibody-based COVID-19 therapies and their potential for easing the strain on economies and healthcare infrastructures during the pandemic (Chen et al., 2020; Jiang et al., 2020; Jones et al., 2020). Key target populations for such monoclonal antibody treatments include immunocompromised individuals, patients that are particularly susceptible due to comorbidities (cardiovascular disease, diabetes, chronic respiratory conditions), and those aged over 65 (Jiang et al., 2020). To date, several antibody therapies targeting the spike (S) protein of SARS-CoV-2 have been successfully used in the fight against the virus (Chen et al., 2020; Gottlieb et al., 2021). One example is Eli Lilly and Companies' bamlanivimab (LY-CoV555), which was the first anti-SARS-CoV-2 monoclonal antibody tested clinically in June 2020, three months after initiating discovery efforts (Jones et al., 2021). Lilly's combination of bamlanivimab with another antibody, etesevimab, has received emergency authorization in several countries. Bamlanivimab is also being assessed with the monoclonal antibody VIR-7831 (GSK4182136) in a clinical setting (Medicine, 2020). Clinical 
testing has shown that antibodies from Regeneron, GSK/Vir, AstraZeneca, and others are also safe and effective (AstraZeneca, 2020; GlaxoSmithKline, 2021; Regeneron, 2021). As variants continue to emerge and spread, antibodies can provide highly effective therapeutic options to vulnerable populations against COVID-19. However, for antibody therapies to be successful, they must retain potent neutralizing breadth against emerging SARS-CoV-2 lineages carrying mutations. A high neutralization potency may also provide the opportunity to explore lower clinical doses (Andreano et al., 2021) and alternate routes of administration.

Multiple reports have consistently shown that mutations in SARS-CoV-2 can substantially reduce the binding affinity and neutralization of antibodies (Rees-Spear et al., 2021; Yao et al., 2021). Variants such as B.1.1.529, B.1.1.7, B.1.351, P.1, B.1.526, B.1.427, and B.1.429 affect the in vitro binding of antibodies being tested clinically or on those already authorized for emergency use to varying degrees (Kuzmina et al., 2021; Liu et al., 2021; Rees-Spear et al., 2021). Mutations at amino acid positions 417, 439, 452, 484, and 501 were found to have the greatest consequences on the functionality of both antibodies and vaccines (Thomson et al., 2021). Therefore, antibodies that retain binding and potent neutralization activity in the presence of these mutations could be extremely valuable tools to rapidly respond to these variants.

In this report, we describe LY-CoV1404 (also known as bebtelovimab), a fully human IgG1 monoclonal SARS-CoV-2 antibody targeting the receptor binding domain (RBD), identified in our ongoing pandemic-response efforts. As of December 2021, LY-CoV1404 binds and potently neutralizes all currently known VOC of SARS-CoV-2 including B.1.1.529 (the Omicron variant). LY-CoV1404 binds to an epitope that is distinct from the mutations identified to be widely circulating within the newly emerged variants, including those mutations that reduce the effectiveness of vaccines. Importantly, the LY-CoV1404 interaction with the S protein is driven by amino acids that are rarely mutated in the global GISAID EpiCoV database, indicating LY- 
CoV1404 has the potential to be a long-term, solution for reducing COVID-19-related illness and death.

\section{$\underline{\text { Results }}$}

\section{Monoclonal antibody LY-CoV1404 retains binding to known variants of SARS-CoV-2}

Variants of SARS-CoV-2 continue to be identified globally (Figure 1A) and can abrogate the binding of monoclonal antibody therapies or reduce vaccine effectiveness (Hoffmann et al., 2021; Wang et al., 2021b). To identify potent neutralizing antibodies to SARS-CoV-2 variants, a highthroughput screening approach (Jones et al., 2021) was conducted on peripheral blood mononuclear cells (PBMC) that were isolated from a COVID-19 convalescent donor. The sample was obtained approximately 60 days after the onset of symptoms.

Three different screening strategies were employed to identify SARS-CoV-2-binding antibodies from the PBMCs in this donor sample. We used a soluble antigen assay with fluorescently labeled prefusion-stabilized full-length trimeric SARS-CoV-2 S protein as well as the SARS-CoV-2 RBD subunit, a live-cell-based assay using mammalian cells that transiently expressed the SARS-CoV$2 \mathrm{~S}$ protein, and a multiplexed bead assay using S proteins from multiple coronaviruses (Figure 1B). A total of 740,000 cells were screened in this discovery effort and machine learning (ML)based analyses were used to automatically select and rank 1,692 antibody "hits" (0.22\% frequency). Of these, 1,062 single antibody-secreting cells were selected for recovery. Libraries of antibody genes from recovered single B cells were generated and sequenced using nextgeneration sequencing, and a custom bioinformatics pipeline with ML-based sequence curation was used to identify paired-chain antibody sequences, with 290 unique high-confidence paired heavy and light chain sequences identified (Figure 1B). The antibody sequences corresponded to 263 clonal families and used a diverse set of $41 \mathrm{VH}$ genes. The mean sequence identity to germline was $96.8 \%$ from this 60 -days post-symptom-onset blood draw in this donor. 
High-throughput SPR experiments on a selected subset of 69 recombinantly-expressed antibodies (including benchmark controls) were performed to assess S protein epitope coverage. These studies included epitope binning, isolated subdomain binding, and binding competition with ACE2 (Figures 1C/S1). We employed 21 benchmark antibodies including those known to bind to S protein subunits $\mathrm{S} 1, \mathrm{~N}$-terminal domain (NTD), RBD, S2 subunit, and several internally identified antibodies with known binding domains. The antibodies (including benchmarks) were clustered into 46 bins using Carterra epitope analysis software based on the competition heatmap (Figure 1C) and were delineated into bins among known subunits of the $S$ protein. Several of the antibodies discovered are cross-blocked with those that are currently in clinical testing or authorized for use in COVID-19 patients including bamlanivimab. We therefore focused analyses on antibodies outside of these established epitopes and identified LY-CoV1404, an ACE2blocking antibody, which is found in a unique bin shared with one other antibody. LY-CoV1404 was observed to compete directly for S protein RBD binding with the S309 (Pinto et al., 2020) and REGN10987 (Hansen et al., 2020) antibodies, suggesting a binding epitope somewhat distinct from other ACE2-blocking antibodies such as bamlanivimab or etesevimab.

Characterization of LY-CoV1404 binding kinetics revealed that the Fab fragment of the antibody bound to the S protein of D614G with high affinity, characterized by binding constant $\left(\mathrm{K}_{\mathrm{D}}\right)$ values ranging between $790 \mathrm{pM}$ and $4 \mathrm{nM}$, depending on the assay (Figure 1D, Table 1). We further analyzed the binding affinity of LY-CoV1404 as a human IgG1 antibody and determined the affinity to be between 75 pM and 220 pM (depending on the assay design) for LY-CoV1404 binding to the $S$ protein (Figure 1E, Table 1). There was no loss of binding to the $S$ protein carrying the D614G mutation (Asp ${ }^{614} \rightarrow$ Gly).

We explored the ability of LY-CoV1404 to bind variant S proteins from the more widely circulating VOC lineages of SARS-CoV-2. LY-CoV1404 retained binding to key VOC including B.1.351 and 
B.1.1.7. Critically, when compared to wild type virus, LY-CoV1404 bound to these variants with no loss in affinity (Figure 1E). These data suggest that LY-CoV1404 binds to a region that is not significantly affected by the prevalent VOC mutations. We further tested the binding of LYCoV1404 to a wider range of S mutants and VOC using an assay system with S protein expressed on the surface of mammalian cells. In these assays, we compared binding of LY-CoV1404 to isotype control antibodies. Consistent with the affinity data, LY-CoV1404 maintained binding to all variants and mutants tested (Figure 1F). These data indicate that SARS-CoV-2 S protein variants identified and reported to be of significant concern in this pandemic are still potently bound by LY-CoV1404.

\section{LY-CoV1404 potently neutralizes SARS-CoV-2 authentic virus and viral variants}

The in vitro viral neutralization activity LY-CoV1404 was assessed against an authentic viral strain (SARS-CoV-2/MT020880.1) using an immunofluorescence assay (IFA) readout. In these studies, LY-CoV1404 potently neutralized the authentic virus with half maximal inhibitory concentration (IC50) values ranging from $9 \mathrm{ng} / \mathrm{mL}$ to $22.1 \mathrm{ng} / \mathrm{mL}$. Bamlanivimab (LY-CoV555), another potent anti-RBD binding antibody, consistently had a 2-3-fold higher (less potent) IC50 compared to LYCoV1404 (Figure 2A).

We also tested the VIR-S309 antibody that was recently described to have a unique binding epitope, outside of many of the mutated positions in current VOC (Pinto et al., 2020). Vir's authorized antibody, Vir-7831, is cross-reactive to SARS-CoV-1 S protein and retains neutralization capacity against all of the current variants of concern (Cathcart et al., 2021). Comparing separate assay runs, we observed VIR-S309 had an IC50 of $118 \mathrm{ng} / \mathrm{mL}$ (highly consistent with a recent report on the clinically active derivative VIR-7831 (Cathcart et al., 2021)) compared to bamlanivimab with a range of 19.2 to $29.7 \mathrm{ng} / \mathrm{mL}$ IC50 in multiple independent assays (Figure 2B). Amongst other antibodies tested, LY-CoV1404 exhibited the most potent 
neutralization of authentic virus in this assay (Figure $2 \mathrm{C}$ ). We also tested authentic virus neutralization in a plaque reduction neutralization test (PRNT) against a Canadian strain of SARSCoV-2 (hCoV-19/Canada/ON_ON-VIDO-01-2/2020) with multiple antibodies (Figure 2C), and against other natural SARS-CoV-2 isolates tested with LY-CoV1404 alone and in combination with other antibodies (Table 2). LY-CoV1404 potently neutralized viral infection in the PRNT assays with IC50 values ranging from 2-10 ng/mL, and there was no evidence of deleterious effects on neutralization when combined with other neutralizing mAbs.

To further characterize the functional activity of LY-CoV1404 against VOCs we tested the neutralization activity in authentic VOC virus assays and pseudotyped neutralization assays with a wider array of VOC and subpopulations. Consistent with the binding data showing high affinity binding to a variety of VOCs and individual mutations, LY-CoV1404 retained full neutralization potency against authentic virus including wild type, B.1.1.7, B.1.351 and B.1.617.2 (Table 3A). In pseudotyped neutralization assays using a wide breadth of VOCs, LY-CoV1404 retained activity against all variants, including prominent VOCs B.1.617.2, B.1.351, B.1.1.529, and P.1 (Table 3B). The rapid spread of the new variant, B.1.1.529 (Omicron), with 35 mutations in the amino acid sequence of the spike protein, and 15 of those mutations located in the RBD, has raised concerns for the activity of a number of clinically tested therapeutic monoclonal antibodies. The ability of these antibodies to neutralize B.1.1.529 was compared in pseudotyped neutralization assays. LYCoV-1404 was the only antibody that retained full potency against the Omicron variant in these assays; separately, Vir-7831 (sotrovimab) has been shown to exhibit a minor loss in neutralization potency (2.7-fold reduction) against this same variant (Cathcart et al., 2021). (Table 3C, 3D). These assays were performed using two different systems with highly comparable results. The data indicate that LY-CoV1404 retains its potency against VOCs, including those dominant or rapidly spreading worldwide (such as B.1.617.2 and B.1.1.529). 


\section{LY-CoV1404 blocks ACE2-Spike interaction and binds to an infrequently mutated RBD} epitope

In order to fully characterize the binding epitope of LY-CoV1404 we determined the X-ray crystal structure of LY-CoV1404 Fab bound to S protein RBD and CryoEM structure of intact S protein bound to LY-CoV1404 (Figure 3). The Fab of LY-CoV1404 binds to a region overlapping the ACE2-interacting site of the S protein that is accessible in both the "up" and "down" conformers of the RBD on the S protein (Figure S2). While this property would suggest that LY-CoV1404 is a Class 2 binder (Barnes et al., 2020), the structural location of the epitope is closer to the canonical Class 3 binder, VIR-S309 (Wang et al., 2021b). Interestingly, the binding epitope of LYCoV1404 is very similar to previously described antibodies imdevimab (REGN10987) (Hansen et al., 2020) and Fab 2-7 (Cerutti et al., 2021; Liu et al., 2020). This similarity is apparent from the structural superposition of the Fabs as well as which RBD residues interact with the antibodies (Figure S3). Furthermore, though independently discovered, LY-CoV1404 and Fab 2-7 (Cerutti et al., 2021) share $92 \%$ amino acid sequence identity in the variable regions of both their heavy and light chains, and they both engage the RBD similarly through their heavy and light chains. By contrast, REGN10987 is more sequence divergent and nearly all of its interactions with the RBD are through its heavy chain. LY-CoV1404 has a contact surface area on the RBD of $584 \AA^{2}$, compared to $496 \AA^{2}$ for Fab 2-7, and only $343 \AA^{2}$ for REGN10987 (Table S2).

To determine the frequency of mutations of the amino acid residues of the S protein that are close contacts with LY-CoV1404 as determined by structural analysis, we used the publicly deposited mutations observed at these sites in the GISAID EpiCoV database (Table 4). There were very few changes to these identified amino acids, with the only two residues below the $>99 \%$ unchanged threshold: N439 and N501 (reported as having $99.371 \%$ and $78.189 \%$ conservation at these positions respectively), demonstrating that the LY-CoV1404 epitope has remained relatively unchanged during the pandemic. We identified the most prevalent mutations at epitope 
residues in the GISAID EpiCoV database and characterized their impact on the functional activity of LY-CoV1404. Interestingly, the observed N439K and N501Y mutations had no impact on LYCoV1404 binding or neutralization (Table 5). The lack of effect by the N493K mutation is interesting in the context of the loss of antibody binding previously observed for REGN10987 (Thomson et al., 2021) demonstrating that beyond the epitope, the specific interactions are critical to determining whether resistant mutations will arise for any particular antibody. A loss of binding, ACE2 competition and neutralization activity was observed with mutations at positions 444 and 445 (which could arise by a single nucleotide change) (Table 5). Importantly however, these changes are extremely rare in the general population as reported in the GISAID database (Table 4). The ability of LY-CoV1404 to maintain neutralization potency despite a variety of mutations that have been shown to nullify activity of several other potent neutralizing antibodies (Rappazzo et al., 2021) indicates that this antibody may be uniquely suited to combat the current VOC. Critically, potent activity against all of these variants suggests that LY-CoV1404 binds to an epitope that has acquired few mutations.

With the exception of N439 and N501, the residues with which LY-CoV1404 interacts are not prevalent in current VOC (e.g. 417, 439, 452, 484). Importantly, while the LY-CoV1404 binding epitope includes residues both N439 and N501, LY-CoV1404 still binds the N501Y mutant (Figure 1F), and variants B.1.1.7 and B.1.351, which both carry the N501Y mutation and are neutralized as potently as wild type virus in both the pseudovirus and live virus assays (Table 3A/B). Similarly, the LY-CoV1404 binding epitope includes residue N439, and substantially overlaps with the binding site of the clinically validated antibody imdevimab (Figure 3B, Figure S2). However, unlike imdevimab (Thomson et al., 2021), LY-CoV1404 retains full functional neutralization against pseudovirus with the N439K mutant (Table 5), indicating that these residues do not play critical roles in LY-CoV1404 interaction with S protein. In addition, the mutations present in B.1.1.529 that reside within the binding epitope for LY-CoV1404, specifically 
G446S, N440K, Q498R, and N501Y, do not impact the neutralization activity of LY-CoV1404. Importantly, potent activity against all the tested variants suggests LY-CoV1404 binds uniquely to an epitope that has acquired few mutations and is not sensitive to the mutations that have arisen to date.

\section{Mutational analysis of S protein binding to LY-CoV1404}

We explored the potential for resistant mutations to arise by yeast-display of the S protein RBD. A library was constructed in which all amino acid residues were sampled at positions 331 to 362 and 403 to 515 of the spike glycoprotein containing the epitope of LY-Cov1404. Cells containing RBD substitutions that were still able to bind soluble ACE2 after antibody treatment were isolated and sequenced to determine the location and identity of the change. Further functional characterizations of isolates were limited to those containing a change of a single amino acid residue which can be generated by a single nucleotide change based on the codon used in the Wuhan isolate sequence.

Consistent with the structure of the RBD complex, selection using LY-CoV1404 identified potential susceptibility to some, but not all, substitutions at residues K444, V445, G446, and P499. None of the observed G446 changes identified from the selection could arise from a single nucleotide substitution but nevertheless suggested a potentially liable residue with LY-CoV1404. The presence of the G446V variant in the GISAID database, as well as the ability of this variant to be resistant to imdevimab treatment prompted further analysis. The ability of LY-CoV1404 to inhibit ACE2 binding to RBD substitutions that have been identified in common circulating viral variants and/or have been shown to impart resistance to the authorized antibodies bamlanivimab, etesevimab, casirivimab, and imdevimab was also analyzed (Table 6). 
We further characterized LY-CoV1404 activity in the presence of mutations known to weaken the effectiveness of other antibodies in clinical testing. Of the mutations tested, only K444Q, V445A, and G446V impacted LY-CoV1404 binding (Table 5). Interestingly, while the K444Q and V445A mutations also resulted in reduced ACE2 competition and neutralization activity, the G446V mutation only appeared to significantly impact the monomeric binding affinity, along with modest changes in ACE2 competition and neutralization. These residues are very rarely mutated according to GISAID reports (Tables 4,5), thus suggesting a low risk of mutations emerging at these residues and restriction in functional activity of LY-CoV1404. We examined the frequency of all variants observed at residues 444 and 445 within the GISAID-EpiCoV database (Shu and McCauley, 2017), as of December 21, 2021; see Materials and Methods). These two sites were rarely mutated, with $0.036 \%$ at residue 444 and $0.014 \%$ at residue 445 of samples collected contain mutations. It is not known whether all variants at these locations would confer resistance. Of the specific mutations tested (Table 5), we find that only $0.0057 \%$ of samples contained the known resistance V445A, while no occurrences of K444Q were observed. This suggests LYCoV1404 may remain effective even as new strains emerge. These data also indicate that LYCoV1404 is not only likely to be highly effective against current variants, but is less likely to be impacted by future mutations given the low level of changes observed to date in its binding epitope (McCormick et al., 2021).

\section{Discussion}

We report the discovery of LY-CoV1404, a highly potent SARS-CoV-2 S protein RBD-binding antibody that maintains binding and neutralizing activity across currently known and reported VOC. LY-CoV1404 binds to or neutralizes variants including B.1.1.529 (Omicron) and those first identified in India (B.1.617.1, B.1.617.2, and B.1.617.3), the UK (B.1.1.7), South Africa (B.1.351), Brazil (P.1), California (B.1.426 and B.1.429), and New York (B.1.526). The neutralizing potency of LY-CoV1404 against either pseudotyped viral mutant reporters or authentic virus indicates that 
the antibody binds to an epitope on the S protein that is accessible and bound with high affinity by LY-CoV1404. In addition, LY-CoV1404 blocks interaction between ACE2 and the S protein, providing a strong, well-documented mechanism for the potent neutralizing activity. Multiple antibodies that rely upon this receptor-blocking mechanism have recently been developed as treatments for COVID-19 and clearly demonstrate that antibody-mediated viral neutralization is a safe and highly efficacious COVID-19 treatment strategy (Chen et al., 2020; Eli Lilly and Company, 2020; Gottlieb et al., 2021; Regeneron, 2021). However, the emergence of SARSCoV-2 variants has diminished the effectiveness of several of these therapeutic antibodies (Davies et al.; Munnink et al., 2021; Plante et al., 2020; Tegally et al., 2021). The rapid spread of a new VOC (B1.1.529, Omicron) has diminished the function of all of the authorized and clinically tested antibodies. Notably, this is true even for two antibodies that have demonstrated crossreactivity to SARS and were believed to be less susceptible to viral escape; ADG20 was found to be more than 300 -fold less potent against B1.1.529, while the potency of $\$ 309$ was reduced by approximately 10-fold. This underscores the unpredictability of SARS-CoV-2 spike mutation. Importantly, LY-CoV-1404 is the only clinically tested antibody that retains full functional potency in pseudotype virus neutralization assays. Our data suggest that LY-CoV-1404 is more than 50-fold more potent against omicron than any of the other clinical stage antibodies we have tested. The unique binding epitope of LY-CoV1404, together with the low frequency of mutations observed within this epitope, indicate that this antibody could provide an effective therapeutic option against current VOCs and emerging variants as a complementary approach to vaccinations and other COVID-19 therapies.

With more than 271 million infections world-wide it is not surprising that SARS-CoV-2 variants with a potential selective advantage have arisen. These resulting variants have acquired either increased affinity for ACE2 binding (Altmann et al., 2021), increased transmissibility and infection severity (Gu et al., 2020), or immune evasion (Altmann et al., 2021), and threaten to reduce the 
effectiveness of currently available vaccinations (Mansbach et al., 2020; Yurkovetskiy et al., 2020). The D614G mutation, reported early in the course of the pandemic, has been determined to stabilize the S protein, leading to more efficient ACE2 interactions and infections (Santos and Passos, 2021). The rapid spread of the B.1.1.7 variant, which contains the key mutation N501Y, has been correlated with increased ACE2 binding affinity (Baric, 2020; Horby et al., 2021; Plante et al., 2020). Certain recurring mutations within the $S$ protein have also been reported in variants from different geographical regions indicating that these common mutations may confer an advantage to the virus (Kuzmina et al., 2021; Liu et al., 2021; Rees-Spear et al., 2021). Reports of particular key mutations such as E484K are present in several variants emerging independently in several geographic locations (South Africa B.1.351, Brazil P.1, New York B.1.526, and recently some UK B.1.1.7 strains) (Xie et al., 2021). Investigations have indicated that vaccine-induced and natural immune responses may not be as effective against variants carrying the E484K mutation (Plante et al., 2020). In addition, several other specific mutations within the S protein have been demonstrated to reduce binding and effectiveness of antibody therapies (Eli Lilly and Company, 2020; Regeneron, 2021). With the proven clinical effectiveness of antibody therapies at preventing hospitalization, reducing severity of disease symptoms and death (Darby and Hiscox, 2021), the importance of access to effective antibody treatments targeting conserved neutralizing epitopes for response to viral variants must be recognized.

It remains unknown whether vaccines will significantly alter the mutation profile of the virus (Choi et al., 2020; Kemp et al., 2021). If, as vaccination continues world-wide, the virus responds to this selection pressure with particular mutations to avoid the effects of vaccination, it will be important to maintain alternative therapies to help overcome these variants. It has been hypothesized that certain variants may have arisen in immunocompromised individuals, which provided the virus with an extended timeframe for continued viral replication and the accumulation of many mutations, seeding these novel VOC (Aschwanden, 2021). A potent neutralizing monoclonal 
antibody, such as LY-CoV1404, would be a potential therapeutic option for these immunocompromised patients, with rapid neutralization of the virus providing both protection for the patient, and less opportunity for viral mutation and evolution. Finally, immunocompromised individuals are less likely to respond well to vaccines, further highlighting the utility of monoclonal antibody therapy for protecting this population. Monoclonal antibodies with potent neutralizing effects could provide a safe and robust medical countermeasure against variants or a necessary, complementary alternative form of protection for those individuals who cannot, or do not receive vaccines. For the reasons listed above, it has been proposed that achieving "herd immunity" is unlikely in the near term for SARS-CoV-2 (Cathcart et al., 2021; Pinto et al., 2020), further emphasizing the need for medical alternatives to combat viral resistance.

Recently, an antibody that binds to an epitope of the SARS-CoV-2 S protein that is distinct from current VOCs has been described. This antibody, VIR-7831(GSK, 2021), binds to and neutralizes current variants of concern, including Delta (B.1.617.2) and Omicron (B.1.1.529), and has recently been reported to have clinical efficacy at a 500mg dose (Cathcart et al., 2021). LY-CoV1404 is equally effective in viral neutralization against all tested variants and importantly is several-fold more potent in viral neutralization assays (Cathcart et al., 2021) (Figure 2B). Though it remains to be tested, this increased potency has the potential to enable lower doses and subcutaneous administration for either treatment or prophylaxis. Interestingly, VIR-7831 was derived from the antibody S309, which was identified from a SARS-CoV-1 convalescent patient (Cathcart et al., 2021). This antibody is cross-reactive to SARS and binds to one of the few epitopes shared between the viruses, which includes an N-linked glycan. By comparison, LY-CoV1404 was discovered from a SARS-CoV-2 convalescent patient and selected based on its cross-reactivity to SARS-CoV-2 variants, thereby allowing testing and identification of much more potent neutralizing epitopes. A more recently identified antibody from a COVID-19-recovered patient, S2X259, was described with broad cross-reactivity to variants (including B.1.1.7, B.1.351, 
B.1.429, and P.1) and several zoonotic strains (Tortorici et al., 2021). This antibody, while able to bind widely to coronaviruses, had neutralizing capacity against SARS-CoV-2 in authentic virusneutralization assays that was substantially less potent than LY-CoV1404. Finally, an engineered antibody with broad cross-reactivity against coronaviruses and potent neutralization was recently described (Rappazzo et al., 2021), which was optimized for binding following identification from a SARS convalescent patient.

Mutations within the S protein and in particular in the RBD are inevitable, particularly as SARSCoV-2 has been present in the human population for only 18 months (Jones et al., 2020). Since the pandemic began, we have continued to screen patient samples and have identified thousands of human antibodies with associated functional data. We analyzed this antibody database in response to the increase in VOC and identified many potential solutions based on these variants. LY-CoV1404 is one example of this screening and analysis. In order to fully prepare for the inevitability of additional mutants and reduction in treatment effectiveness, we propose expanding this effort into a panel of potent neutralizing antibodies with full coverage of the S protein RBD. The antibodies in this panel, if well characterized and advanced to (at minimum) research cell banks (RCBs), could accelerate key manufacturing steps and be rapidly deployed. This strategy of a panel of antibodies would enable a rapid response to any emerging variant, necessitating only mutation identification and assessment of binding and neutralization of a new mutation arising in a particular geography. The rapid deployment of the antibody into clinical testing could follow immediately after identification of novel VOC. This stands as a desirable rapid countermeasure to safeguard ongoing pandemic responses, especially as antibodies, if administered early in the course of disease or prophylactically, have demonstrated to be safe and effective for combatting SARS-CoV-2 infection. The antibody described in this report, LYCoV1404, is a key member of such a panel, especially given its retention of potency against a variety of emerging viral variants. The rapid development of this antibody and entry into clinical 
testing concurrent with this report represents a significant milestone in response to the evolving pandemic.

\section{Materials and Methods}

Materials

Recombinant antibodies and other proteins were produced as previously described (Jones et al., 2020). The antigen binding fragment (Fab) portion of LY-CoV1404 was generated by proteolytic digestion using immobilized papain (ThermoFisher Scientific), followed by removal of un-cleaved protein using standard chromatography techniques. The reference S protein sequence was from strain hCoV-19/Wuhan/IVDC-HB-01/2019 (EPI_ISL_402119). The isolated RBD, residues 328 to 541 of the S protein, was fused to a linker sequence containing a TEV-protease recognition site, followed by a human IgG1 Fc sequence. Fc-fusions of either the reference sequence, or containing mutations, were expressed in $\mathrm{CHO}$ cells and purified. The extracellular domain (ECD, residues 18 to 618) of ACE2 was expressed in $\mathrm{CHO}$ cells as an Fc-fusion protein containing a TEV-protease recognition site. Monomeric ACE2 ECD was generated by TEV protease digestion and purification of the ACE2 using standard chromatography techniques. For protein crystallization experiments, the isolated receptor binding domain (RBD, residues 329 to 527 of the $\mathrm{S}$ protein), was fused to a 6 -His tag at the C-terminus, expressed in $\mathrm{CHO}$ cells, captured by $\mathrm{Ni+-based} \mathrm{immobilized} \mathrm{metal} \mathrm{affinity} \mathrm{chromatography,} \mathrm{enzymatically} \mathrm{de-glycosylated} \mathrm{using}$ endoglycosidase- $\mathrm{H}$, and purified by cation exchange chromatography. The Fab portion of LYCoV1404, containing mutations in the constant region known to encourage crystallization, LYCoV1404-CK Fab (Lieu et al., 2020a), was expressed in $\mathrm{CHO}$ cells, and purified by standard chromatography techniques. The Fab:RBD complex was prepared by mixing the components with $20 \%$ molar excess of the RBD, and then the complex purified from the excess RBD by sizeexclusion chromatography. 
Single-cell screening and recovery

A blood sample from a 35-year-old individual hospitalized with severe COVID-19 disease was obtained in early-2020, approximately 60 days following the onset of symptoms. PBMC samples were collected under institutional review board (IRB)-approved protocols as part of the Hospitalized and Ambulatory Adults with Respiratory Viral Infections (HAARVI) study at the University of Washington (protocol \#STUDY00000959) and Vaccine Research Center (VRC), National Institute of Allergy and Infectious Diseases (NIAID) and National Institutes of Health $(\mathrm{NIH}$; protocol-VRC400, NIH-07IN194). Cells were thawed, activated in culture to generate antibody secreting cells and enriched for B cell lineage cells prior to injection into AbCellera's microfluidic screening devices with either 91,000 or 153,000 individual nanoliter-volume reaction chambers (46-54). Single cells secreting target-specific antibodies were identified and isolated using three assay types (55): a multiplexed bead assay using multiple optically-encoded beads, each conjugated to the soluble pre-fusion stabilized S protein of either SARS-CoV-2 or WIV1 S with T4-foldon domain, $3 \mathrm{C}$ protease cleavage site, 6x His-tags, and twin-strep tags (34), the SARS-CoV-2 S1 subunit or negative controls (bovine serum albumin [BSA] His-tag and T4 FoldOn trimerization domain), and a live cell assay using passively dyed suspension-adapted Chinese hamster ovary $(\mathrm{CHO})$ cells transiently transfected to surface-express full-length SARSCoV-2 S protein (GenBank ID MN908947.3) with a green fluorescent protein (GFP) reporter, and non-transfected cells as a negative control. For the soluble assay, the IgG secreted by B-cells was captured on beads using the constant region. Binding to secreted IgG immobilized onto beads was subsequently assessed using soluble fluorescently labeled SARS-CoV-2 S or SARSCoV-2 RBD antigen.

Beads or cells were flowed onto microfluidic screening devices and incubated with single antibody-secreting cells, and mAb binding to cognate antigens was detected via a fluorescently labeled anti-human IgG secondary antibody, or soluble antigen labeled with fluorophore. Positive 
hits were identified using machine vision and recovered using automated robotics-based protocols.

Single-cell sequencing, bioinformatic analysis, and cloning

Single cell polymerase chain reaction (PCR) and custom molecular biology protocols generated NGS sequencing libraries (MiSeq, Illumina) using automated workstations (Bravo, Agilent). Sequencing data were analyzed using a custom bioinformatics pipeline to yield paired heavy and light chain sequences for each recovered antibody-secreting cell (Jones et al., 2020). Each sequence was annotated with the closest germline $(V(D) J)$ genes, degree of somatic hypermutation, and potential sequence liabilities. Antibodies were considered members of the same clonal family if they shared the same inferred heavy and light $\mathrm{V}$ and $\mathrm{J}$ genes and had the same CDR3 length. The variable $(\mathrm{V}(\mathrm{D}) \mathrm{J})$ region of each antibody chain was PCR amplified and inserted into expression plasmids using a custom, automated high-throughput cloning pipeline. Plasmids were verified by Sanger sequencing to confirm the original sequence previously identified by NGS. Antibodies were recombinantly produced by transient transfection in either human-embryonic kidney (HEK293) or CHO cells as described in Supplemental Methods.

\section{Epitope binning}

All epitope binning and ACE-2 blocking experiments were performed on a Carterra ${ }^{\circledR}$ LSA $^{\mathrm{TM}}$ instrument equipped with an HC-30M chip type (Carterra-bio), using a 384-ligand array format as previously described(Shu and McCauley, 2017). For epitope binning experiments, antibodies coupled to the chip surface were exposed to various antibody:antigen complexes. Samples were prepared by mixing each antibody in 10-fold molar excess with antigen (1:1 freshly prepared mix of $400 \mathrm{nM}$ antibody and $40 \mathrm{nM}$ antigen, both diluted in 1X HBSTE + 0.05\% BSA running buffer). Each antigen-antibody premix was injected sequentially over the chip surface for 5 minutes 
(association phase to ligand printed onto chip previously), followed by a running buffer injection for 15 minutes (dissociation phase). Two regeneration cycles of 30 seconds were performed between each premix sample by injecting $10 \mathrm{mM}$ glycine $\mathrm{pH} 2.0$ onto the chip surface. An antigenonly injection ( $20 \mathrm{nM}$ concentration in the running buffer) was performed every 8 cycles to assess maximum binding to $S$ protein and in-order to accurately determine the binning relationship.

The data were analyzed using the Carterra Epitope analysis software for heat map and competition network generation. Analyte binding signals were normalized to the antigen-only binding signal, such that the antigen-only signal average is equivalent to one RU (response unit). A threshold window ranging from $0.5 \mathrm{RU}$ to $0.9 \mathrm{RU}$ was used to classify analytes into 3 categories: blockers (binding signal under the lower limit threshold), sandwichers (binding signal over the higher limit threshold) and ambiguous (binding signal between limit thresholds). Antibodies with low coupling to the chip, poor regeneration or with absence of self-blocking were excluded from the binning analysis. Like-behaved antibodies were automatically clustered to form a heat map and competition plot.

To test the antibodies' ability to block ACE2, antibodies coupled to the HC-30M chip as described above were exposed to SARS-CoV-2 S protein:ACE2 complex. A freshly prepared 1:1 mix of 40 $\mathrm{nM}$ of SARS-CoV-2 S protein and $400 \mathrm{nM}$ of untagged ACE2, both diluted in HBSTE $+0.05 \%$ BSA, were tested for binding to the immobilized mAbs on the prepared HC-30M chips, with association for 5 minutes and dissociation for 5 minutes. A SARS-CoV-2 S protein injection at 20 $\mathrm{nM}$ was included to assess for maximum binding, as well as a ACE2 injection at $200 \mathrm{nM}$ to assess for non-specific binding. Regeneration was performed in $20 \mathrm{mM}$ glycine $\mathrm{pH} 2.0$ with $1 \mathrm{M} \mathrm{NaCl}$ for 30 seconds twice.

Single-cycle kinetics on Biacore 
Surface plasmon resonance (SPR) capture experiments were performed on a Biacore $8 \mathrm{~K}$ instrument equipped with a SA chip type (Cytiva, USA). The instrument uses one microfluidic module, an 8 multi-flow channel, to deliver samples to the chip surface via a unidirectional flow of sample at a set flow rate and concentration. The chip contains 8 flow cells, i.e. up to 8 ligands can be captured and analyzed at the same time. Streptavidin is pre-coated on the chip by the manufacturer.

Single cycle kinetics of LY-CoV1404 in Fab format was performed using the SA chip on the Biacore instrument as described herein. The chip was pre-conditioned with 3 injections of $10 \mathrm{mM}$ $\mathrm{NaOH}$ buffer for $30 \mathrm{sec}$ each, at a flow rate of $10 \mathrm{uL} / \mathrm{min}$. The antigen of interest displaying a Strep tag was diluted to $5 \mathrm{nM}$ in HBS-EP+ buffer (10 mM HEPES, $150 \mathrm{mM} \mathrm{NaCl}, 3 \mathrm{mM}$ EDTA and $0.05 \% \mathrm{v} / \mathrm{v}$ Surfactant P20), then flowed over the SA chip for $60 \mathrm{sec}$ at a flow rate of $10 \mathrm{uL} / \mathrm{min}$. Fab LY-CoV1404 was diluted in HBS-EP+ buffer to various concentrations ( 300 nM, 100 nM, 33.3 $\mathrm{nM}, 11.1 \mathrm{nM}, 3.7 \mathrm{nM}, 1.2 \mathrm{nM})$. Each concentration was then serially flown over, from lowest concentration to highest, starting with a buffer (blank) injection, for $120 \mathrm{sec}$ at a flow rate of 30 $\mathrm{uL} / \mathrm{min}$. After the Fab injections, HBS-EP+ buffer was injected for $600 \mathrm{sec}$ at a flow rate of 30 $\mathrm{uL} / \mathrm{min}$. Finally, the chip was regenerated with a single injection of $10 \mathrm{mM}$ Glycine, $\mathrm{pH} 2.0$ for 30 $\mathrm{s}$ at a flow rate of $30 \mathrm{uL} / \mathrm{min}$.

The data were analyzed using the Biacore Insight Evaluation Software and the pre-defined single cycle kinetics method. The curves were reference and blank subtracted and then fit to a $1: 1$ Langmuir binding model to generate association (ka) and dissociation (kd) kinetic rate constants and binding affinity constants (KD). 
A Carterra ${ }^{\circledR}$ LSA $^{\text {TM }}$ instrument was used to measure binding kinetics of LY-CoV1404 to SARSCoV-2 S protein, D614G S protein variant, RBD (receptor-binding domain) protein and mutant RBDs. Assays were performed according to the manufacturer's operational guidelines. The instrument used a multi-channel buffer of $25 \mathrm{mM}$ 2-(N-morpholino) ethanesulfonic acid (MES), $\mathrm{pH}$ 5.5, and a single-channel buffer of 10 mM 2-[4-(2-hydroxyethyl)piperazin-1-yl]ethanesulfonic acid (HEPES), $150 \mathrm{nM} \mathrm{NaCl}, 3$ mM EDTA, and 0.05\% v/v surfactant P20 (HBS-EP+).

To investigate binding of LY-CoV1404 mAb to SARS-CoV-2 S protein, D614G S protein variant and RBD protein, a HC30M chip was used, and the array preparation was performed as described above, coupling antibody diluted to $3 \mu \mathrm{g} / \mathrm{mL}$ in $10 \mathrm{mM}$ acetate, $\mathrm{pH} 4.0$, for 10 minutes, and deactivation for 7 minutes in $1 \mathrm{M}$ ethanolamine, $\mathrm{pH} 8.5$.

To measure binding kinetics and affinity, the mAb-coupled HC30M chip surface was exposed to injections of the proteins, with an association period of 5 minutes and dissociation period of 15 minutes. The tested concentrations of the trimeric $S$ proteins were $300,100,33.3,11.1,3.70$, 1.23, and $0.41 \mathrm{nM}$ in HBS-EP+ containing $0.1 \mathrm{mg} / \mathrm{mL}$ BSA. The tested concentrations of the RBD protein were 400, 100, 25, 6.25 and $1.56 \mathrm{nM}$ in HBS-EP+ containing $0.1 \mathrm{mg} / \mathrm{mL}$ BSA. Regeneration of the chip surface between the different concentrations was performed using 20 $\mathrm{mM}$ glycine, $\mathrm{pH} 2.0$, for 30 seconds twice. Kinetic data was analyzed using Carterra KIT ${ }^{\mathrm{TM}}$ software using a 1:1 Langmuir binding model.

To investigate binding of LY-CoV1404 Fab to reference and mutant RBDs a HC30M chip was used, and the array preparation was performed as described above, coupling Fc-fused RBD proteins diluted $5 \mu \mathrm{g} / \mathrm{mL}$ and $10 \mu \mathrm{g} / \mathrm{mL}$ in $10 \mathrm{mM}$ acetate, $\mathrm{pH} 4.0$, for 10 minutes, and deactivation for 7 minutes in $1 \mathrm{M}$ ethanolamine, $\mathrm{pH} 8.5$.

To measure binding kinetics and affinity, the RBD-coupled HC30M chip surface was exposed to injections of LY-CoV1404 Fab, with an association period of 5 minutes and dissociation period of 
15 minutes. The tested concentrations of LY-CoV1404 Fab were 300, 100, 33.3, 11.1, 3.70, 1.23, and $0.41 \mathrm{nM}$ in HBS-EP+ containing $0.1 \mathrm{mg} / \mathrm{mL}$ BSA. Regeneration of the chip surface between the different concentrations was performed using $20 \mathrm{mM}$ glycine, $\mathrm{pH} 2.0$, for 30 seconds twice. Kinetic data was analyzed using Carterra $\mathrm{KIT}^{\mathrm{TM}}$ software using a 1:1 Langmuir binding model or steady state model for samples that resulted in a poor 1:1 binding fit. Mutations where binding was observed but neither model resulted in good fits were reported as having affinities greater than the highest concentration of analyte tested. The reported affinity values are averages of multiple measurements for most variants, but the number of replicates varied depending on the variant and ranged from 2 to 26 replicate measurements.

\section{Multi-cycle kinetics on Biacore}

The capture molecule, an anti-human $\operatorname{lgG}(\mathrm{Fc})$ antibody, was immobilized on a Biacore CM5 chip by direct coupling. The chip surface was first activated by flowing a freshly prepared 1:1 activation mixture of $100 \mathrm{mM}$ S-NHS, $400 \mathrm{mM}$ EDC for $10 \mathrm{~min}$ at a flow rate of $10 \mathrm{uL} / \mathrm{min}$. Anti-human IgG (Fc) antibody was diluted to $25 \mathrm{ug} / \mathrm{mL}$ in $10 \mathrm{mM}$ Sodium Acetate buffer $\mathrm{pH} 4.5$, then injected using all 8 channels, at a flow rate of $10 \mathrm{uL} / \mathrm{min}$ for $10 \mathrm{~min}$. The chip was washed with HBS-EP+(10 mM HEPES, $150 \mathrm{mM} \mathrm{NaCl}, 3 \mathrm{mM}$ EDTA and 0.05\% v/v Surfactant P20) for $1 \mathrm{~min}$, at a flow rate of $30 \mathrm{uL} / \mathrm{min}$. Finally, excess reactive esters were quenched by flowing $1 \mathrm{M}$ ethanolamine for 10 min at a flow rate of $10 \mathrm{uL} / \mathrm{min}$, followed by 3 conditioning steps of $30 \mathrm{~s}$ each, in $10 \mathrm{mM} \mathrm{NaOH}$ buffer, at a flow rate of $10 \mathrm{uL} / \mathrm{min}$.

Multi cycle kinetics of LY-CoV1404 was performed using the previously prepared CM5 chip on the Biacore instrument as described herein. LY-CoV1404 was diluted to $5 \mathrm{nM}$ in HBS-EP+ buffer (as above), then flowed over the CM5 chip for $30 \mathrm{sec}$ at a flow rate of $10 \mathrm{uL} / \mathrm{min}$. Each antigen of interest was diluted in HBS-EP+ buffer to various concentrations (100 nM, 33.3 nM, 11.1 nM, 3.7 $\mathrm{nM}, 1.2 \mathrm{nM})$. Each concentration was then serially flown over, from lowest concentration to 
highest, starting with a buffer (blank) injection, for $120 \mathrm{sec}$ at a flow rate of $30 \mathrm{uL} / \mathrm{min}$. After each antigen injection, HBS-EP+ buffer was injected for $600 \mathrm{sec}$ at a flow rate of $30 \mathrm{uL} / \mathrm{min}$. Then the chip was regenerated with a single injection of $3 \mathrm{M} \mathrm{MgCl} 2$ for $30 \mathrm{~s}$ at a flow rate of $30 \mathrm{uL} / \mathrm{min}$ before the next antigen injection.

The data were analyzed using the Biacore Insight Evaluation Software. The curves were referenced and blank subtracted and then fit to a 1:1 Langmuir binding model to generate apparent association (ka) and dissociation (kd) kinetic rate constants and binding affinity constants (KD).

\section{Cell-based binding assay}

Unique antibody sequences were confirmed to bind the screening target (SARS-CoV-2 full length S protein) using high throughput flow cytometry. $\mathrm{CHO}$ cells were transiently transfected to express the full-length S protein of either wild type SARS-CoV or SARS-CoV-2 or mutant SARS-CoV-2 (R21I, T22I, T29I, H49Y, D138H, Q490E, N439K, G476S, S477N, T478I, V483A, F490S, S494P, N501Y, G504D, A520S, D614G, B.1.1.7, B.1.351) on the cell surface. Suspension CHO cells were transiently transfected with the plasmid using electroporation. Full length native conformation $\mathrm{S}$ protein expression was confirmed by testing with benchmark antibodies discovered against SARS-CoV that target different stalk and head domains using flow cytometry.

Purified antibodies at 50nM antibody concentration were incubated with the readout cells or an untransfected control $\mathrm{CHO}$ cells for 30 minutes at $4^{\circ} \mathrm{C}$. $\mathrm{CHO}$ cells were washed, and binding was detected by using a fluorescently labeled anti-human secondary antibody. Fluorescence was measured using high throughput plate-based flow cytometry. Benchmark antibodies identified to bind to SARS-CoV were used as positive controls due to similarity in S protein sequences between SARS-CoV and SARS-CoV-2; human IgG isotype and an irrelevant antibody were used as negative controls. Median fluorescence intensity of each antibody was normalized over the 
median fluorescence intensity of the human isotype control for respective antigens. The median fold over isotype values from different validation experiments were plotted. Antibody values greater than 5-fold over isotype were considered as binders. The cut-off value was determined based on the binding to the negative controls.

\section{Pseudovirus Production and Characterization}

Mutagenesis reactions were performed using the QuickChange Lightning Site-Directed Mutagenesis Kit (Agilent Cat \# 210519) using as template a S protein mammalian expression vector based on the Wuhan sequence (Genbank MN908947.3) with a deletion of the C-terminal 19 amino acids. Pseudoviruses bearing mutant $S$ proteins were produced using the $\Delta G$ luciferase recombinant vesicular stomatitis virus (rVSV) system (KeraFast EH1025-PM)(Whitt, 2010). Briefly, 293T cells were transfected with individual mutant spike expression plasmids, and 16 to 20 hours later, transfected cells were infected with VSV-G-pseudotyped $\Delta$ Gluciferase rVSV. Sixteen to 20 hours following infection, conditioned culture medium was harvested, clarified by centrifugation at $1320 \times \mathrm{g}$ for 10 minutes at $4^{\circ} \mathrm{C}$, aliquoted, and stored frozen at $-80^{\circ} \mathrm{C}$. Infectious titers were determined for a subset of virus preparations by infection of VeroE6 cells (ATCC CRL1586) with serially diluted virus followed by staining with an anti-luciferase antibody (Novus Cat \# NB600-307PEATT594) and analysis by fluorescence-activated cell sorting using a Becton Dickinson LSRFortessaTM X-20. Particle titers were determined by isolation of genomic RNA and quantitation by RT-qPCR (NEB \# E3031) using an Applied Biosystems vii7A ${ }^{\text {TM }}$ Real-Time PCR system. Relative luciferase reporter signal read-out was determined by luciferase assay (Promega Cat \# E2650) of extracts from VeroE6 cells infected with serially diluted virus. Luciferase activity was measured on a PerkinElmer EnVision 2104 multilabel reader. 
Neutralization assays were carried out as described (Nie et al., 2020). Virus preparation volumes were normalized to equivalent signal output (RLU, relative light units) as determined by luciferase activity following infection with serially diluted virus. Eleven-point, 2-fold titrations of LY-CoV1404 were performed in 96-well plates in duplicate and pre-incubated with a fixed amount of pseudovirus for 20 minutes at $37^{\circ} \mathrm{C}$. Following pre-incubation, the virus-antibody complexes were added to 20,000 VeroE6 cells/well in white, opaque, tissue culture-treated 96 well plates, and incubated 16 to 20 hours at $37^{\circ} \mathrm{C}$. Control wells included virus only (no antibody, quadruplicate) and cells only (duplicate). Following infection, cells were lysed, and luciferase activity was measured.

\section{Pseudotyped lentivirus Neutralization Assays}

SARS-CoV-2 spike pseudotyped lentiviruses that harbor a luciferase reporter gene were produced and neutralization assay was performed as described previously (Corbett et al., 2020; Naldini et al., 1996). Pseudovirus was produced by co-transfection of 293T cells with plasmids encoding the lentiviral packaging and luciferase reporter, a human transmembrane protease serine 2 (TMPRSS2), and SARS-CoV-2 S (Wuhan-1, Genbank \#: MN908947.3; D614G and B.1.1.529 containing A67V, H69-, V70-, T95I, G142D, V143-, Y144-, Y145-, N211-,L212I, ins214EPE, G339D, S371L, S373P, S375F, K417N, N440K, G446S, S477N, T478K, E484A, Q493R, G496S, Q498R, N501Y, Y505H, T547K, D614G, H655Y, N679K, P681H, N764K, D796Y, N856K, Q954H, N969K, L981F amino acid changed compared to WA-1) or S variant genes (Wang et al., 2021a) using Lipofectamine 3000 transfection reagent (ThermoFisher, CA). Forty-eight hours after transfection, supernatants were harvested, filtered and frozen. For neutralization assay serial dilutions ( 2 dilutions at 10 and $1 \mu \mathrm{g} / \mathrm{ml}$ for the initial screen assay or 8 dilutions for the full curve at $10-0.0006 \mu \mathrm{g} / \mathrm{ml}$ ) of monoclonal antibodies were mixed with titrated pseudovirus, incubated for 45 minutes at $37{ }^{\circ} \mathrm{C}$ and added to pre-seeded 293T-ACE2 cells (provided by Dr. Michael Farzan) or 293 flpin-TMPRSS2-ACE2 cells (made by Adrian Creanga, 
VRC, NIH) in triplicate in 96-well white/black Isoplates (Perkin Elmer). Following 2 hours of incubation, wells were replenished with $150 \mu \mathrm{L}$ of fresh medium. Cells were lysed 72 hours later, and luciferase activity (relative light units, RLU) was measured. Percent neutralization was normalized considering uninfected cells as $100 \%$ neutralization and cells infected with only pseudovirus as $0 \%$ neutralization. Neutralization IC50, IC80 and IC90 titers were calculated using GraphPad Prism 8.0.2.

Yeast-display identification of escape mutation positions and ACE2 competition

The potential for SARS-CoV-2 to develop resistance under selective pressure of LY-CoV1404, was studied using in vitro directed evolution. The RBD comprised of residues 319 to 541 of SARSCoV-2 S protein (Wuhan sequence, Genbank MN908947.3) was expressed on the surface of yeast cells. Surface-bound RBD was confirmed to be reactive with recombinant soluble hACE2 and LY-CoV1404 by flow cytometry. Soluble hACE2 used for in vitro selection screens (Agro BioSciences Cat \# AC2-H82E6) comprised residues 18 to 634 of Uniprot Q9BYF1 and contained a C terminus Avi tag to enable fluorescence after binding to streptavidin labeled with phycoerythrin. A library was constructed in which all amino acid residues were sampled at positions 331 to 362 and 403 to 515 of the spike glycoprotein. RBD variants that could still bind 4 nM hACE2 in the presence of antibody at $5 \mathrm{nM}$ (14-fold IC50) concentration were isolated after multiple rounds of selection by fluorescence activated cell sorting and sequenced. Detailed characterization of isolated variants was limited to clones that contained only single amino acid changes and that could occur by a single nucleotide change within the codon to better reflect errors that can arise during viral replication in vivo. Additionally, clones containing specific variants of interest observed from public databases and/or shown to be resistant with other authorized monoclonal antibodies were analyzed. 
LY-CoV1404 inhibition of binding to soluble hACE2 used a flow cytometry assay to calculate IC50 for RBD variants of interest expressed on the surface of yeast. The in vitro inhibition assay used $1 \mathrm{nM}$ soluble hACE2 incubated with increasing concentrations of LY-CoV1404, ranging from 0 to $3.75 \mathrm{ug} / \mathrm{mL}$ with each yeast RBD variant of interest. Soluble hACE2 binding was performed at room temperature for 20 minutes followed by transfer of reactions to ice for another 10 minutes to quench dissociation. Fluorescence was measured after addition of streptavidin-phycoerythrin for 20 minutes on ice followed by multiple washes with cold buffer. Mean fluorescence intensity (MFI) was normalized for each concentration response curve (CRC) using the maximum MFI at no mAb inhibitor (MAX) and the background MFI (Bgnd). Percent inhibition of S protein binding to ACE2 was defined as follows:

$$
\text { Percent inhibition }=(\text { MAX }-x) /(\text { MAX }- \text { Bgnd }) \times 100 \%
$$

where $\mathrm{x}$ was the MFI at the tested concentration of mAb. CRCs were fit with a four-parameter logistic function. All four parameters were estimated from the fitting. Absolute IC50 (50\% absolute inhibition) values were reported. Standard error and 95\% confidence intervals for IC50 estimates are reported and, in some cases, a fixed top (Top =100) was used to stabilize the standard error estimate. IC50 ratios between mutant S protein and wild type (WT) were reported. For mutant S proteins that exhibited no mAb inhibition, fold-change was reported at $1 \mathrm{x}$ of the highest concentration of $\mathrm{mAb}$ tested. For any single experimental batch, inhibition data were obtained in duplicate or triplicate. WT RBD was analyzed with every experiment and the consensus estimate as of the date indicated is reported. If select mutants of interest were analyzed in more than one experimental batch, then the geometric mean is reported.

\section{Authentic SARS-CoV-2 Neutralization}

SARS-CoV-2 Stock Preparation. Work with authentic SARS-CoV-2 at USAMRIID was completed in BSL-3 laboratories in accordance with federal and institutional biosafety standards and 
regulations. Vero-76 cells were inoculated with SARS-CoV-2 (GenBank MT020880.1) at a MOI = 0.01 and incubated at $37^{\circ} \mathrm{C}$ with $5 \% \mathrm{CO} 2$ and $80 \%$ humidity. At $50 \mathrm{~h}$ post-infection, cells were frozen at $-80^{\circ} \mathrm{C}$ for $1 \mathrm{~h}$, allowed to thaw at room temperature, and supernatants were collected and clarified by centrifugation at $\sim 2,500 \times \mathrm{g}$ for $10 \mathrm{~min}$. Clarified supernatant was aliquoted and stored at $-80^{\circ} \mathrm{C}$. Sequencing data from this virus stock indicated a single mutation in the $\mathrm{S}$ glycoprotein (H655Y) relative to Washington state isolate MT020880.1.

Authentic SARS-CoV-2 plaque reduction assays were also conducted in BSL3 laboratories at UTMB. Three natural isolates were used to measure mAb neutralization: USA/WA/1/2020 (BEI resources number NR52281), Italy-INMI1 (European Virus Archive - Global, Ref \#008V03893), and the Netherlands (1363454/NL/2020). The NL isolate is known to carry the D614G S protein variation. For studies conducted with variant viruses, virus isolates were constructed using reverse genetics (in the case of the rWA1, rWA1 E484K, and rWA1 E484Q viral isolates), or from patient isolates expanded in cell culture (in the case of the WA1, B.1.1.7, and B.1.351 viral isolates). Methods for the recombinant virus generation are described in detail in a recent publication (Xie et al. 2021). In brief, a viral cDNA encoding the WA strain of SARS-CoV-2 was designed to express authentic virus containing spike genes corresponding to either wild-type, E484K or the E484Q sequence. For naturally occurring variants, four clinical isolates were used as the inocula: USA/WA/1/2020 (BEI Resources NR52281), B.1.351 (USA/MD-HP01542/2021, UTMB WRCEVA collection), B.1.1.7 (USA/CA_CDC_5574, UTMB WRCEVA collection) and B.1.617.2 (GNL-751-TVP23523, UTMB WRCEVA collection). All three variant strains were characterized by NGS sequencing at UTMB to confirm the expected spike protein mutations: B.1.1.7 contained $\Delta 69-70 / \Delta 145 / N 501 Y / A 570 D / D 614 G / P 681 H / R 682 Q / T 716 I / S 982 A / D 1118 H$; B.1.351 contained L18F/D80A/D215G/A242-244/K417N/E484K/N501Y/D614G/A710V; and B.1.617.2 contained T19R/G142D/D156157/R158G/A222V/L452R/T478K/D614G/P681R/R685H/D950N/V1264L. Recombinant virus 
isolates (in the case of the rWA1, rWA1 E484K, and rWA1 E484Q viral isolates) were constructed using reverse genetics as previously described (Xie et al., 2021b). Virus stocks were grown by inoculating cultured Vero E6 cells, followed by incubation at $37^{\circ} \mathrm{C}$ until cytopathic effects (CPE) were evident (typically 48 to 72 hours). Expansion was limited to 1 to 2 passages in cell culture to retain integrity of the original viral sequence. The virus stock was quantified by standard plaque assay, and aliquots were stored at $-80^{\circ} \mathrm{C}$. A freshly thawed aliquot was used for each neutralization experiment.

\section{Authentic SARS-CoV-2 IFA neutralization assay}

A pre-titrated amount of authentic SARS-CoV-2/MT020880.1, at final multiplicity of infection of 0.2 , was incubated with serial dilutions of monoclonal antibodies for $1 \mathrm{~h}$ at $37^{\circ} \mathrm{C}$. The antibodyvirus mixture was applied to monolayers of Vero-E6 cells in a 96-well plate and incubated for 1 hour at $37^{\circ} \mathrm{C}$ in a humidified incubator. Infection media was then removed, and cells were washed once with 1 X PBS, followed by addition of fresh cell culture media. Culture media was removed 24 hours post infection and cells were washed once with 1X PBS. PBS was removed and plates were submerged in formalin fixing solution, then permeabilized with $0.2 \%$ Triton-X for 10 minutes at room temperature and treated with blocking solution. Infected cells were detected using a primary detection antibody recognizing SARS-CoV-2 nucleocapsid protein (Sino Biological) following staining with secondary detection antibody (goat $\alpha$-rabbit) conjugated to AlexaFluor 488. Infected cells were enumerated using the Operetta high content imaging instrument and data analysis was performed using the Harmony software (Perkin Elmer).

\section{PRNT assay (Figure 2)}

Vero-E6 cells were seeded in a 24 -well plate 48 hours before the assay. Seventy-five plaque forming units (pfu) of infectious clone hCoV-19/Canada/ON_ON-VIDO-01-2/2020 were mixed with serial dilutions of monoclonal antibodies and incubated at $37^{\circ} \mathrm{C}$ for 60 minutes. Virus and 
antibody mix was added to each well and incubated for $1 \mathrm{~h}$ in a $37^{\circ} \mathrm{C}+5 \% \mathrm{CO} 2$ incubator with rocking every $10-15$ min. Plaque assay media (complete MEM media with $1 \%$ BGS $+1 \%$ low melting point agarose) was overlaid on top of the inoculum and incubated at $37^{\circ} \mathrm{C}+5 \% \mathrm{CO} 2$ incubator for 48 hours. For plaque visualization, an MEM-Neutral Red overlay was added on day 2 and plaques counted manually on day 3 or day 4 .

PRNT assay (Table 2).

Plaque Reduction Neutralization test assays were performed in 6-well plates. Vero E6 cells were seeded at a concentration of approximately 106 cells/well and grown overnight at $37^{\circ} \mathrm{C}$ in $5 \%$ CO2 to reach $95 \%$ confluency. The next day, serial three-fold dilutions of LY-CoV1404 or bamlanivimab were prepared in Eagle's minimal essential medium, mixed with approximately 100 pfu of SARS-CoV-2, and incubated for 1 to 2 hours on ice or at $37^{\circ} \mathrm{C}$. The mAb/virus mixture was inoculated directly onto the cells (in duplicate wells) and allowed to adsorb for 1 hour at $37^{\circ} \mathrm{C}$ with $5 \%$ CO2, with rocking at 15 -minute intervals. An overlay media composed of $1.25 \%$ Avicel RC 581 (FMC BioPolymer) in Eagles minimum essentials medium (MEM) with 5\% FBS was added, and plates were incubated for 48 hours at $37^{\circ} \mathrm{C}$ with $5 \% \mathrm{CO} 2$ for virus plaques to develop. After incubation, overlays were removed by aspiration and the cells were fixed with $10 \%$ buffered formalin containing crystal violet stain for 1 hour. Plaques were counted manually, and plaque forming units were determined by averaging technical replicates per sample. Percent neutralization was determined relative to virus-only control-treated samples.

\section{Protein Crystallography}

A $10 \mathrm{mg} / \mathrm{mL}$ solution of LY-CoV1404 Fab (with CrystalKappa mutations (Lieu et al., 2020b)) in complex with RBD was set up in vapor diffusion sitting drops at a ratio of $1: 1$ with a well solution of $100 \mathrm{mM}$ Tris $\mathrm{HCl} \mathrm{pH} 6.5,20$ \% PEG MME 2K and 200 mM Trimethylamine N-oxide. Crystals appeared within two days, grew to their full size and were harvested on the fifth day after the set 
up. Crystals were flash-frozen in liquid nitrogen following 1-minute incubation in cryoprotectant solution containing mother liquor supplemented with additional 5\% PEG MME 2K.

Diffraction data were collected at Lilly Research Laboratories Collaborative Access Team (LRLCAT) and beamline at Sector 31 of the Advanced Photon Source at Argonne National Laboratory, Chicago, Illinois. Crystals stored in liquid nitrogen were mounted on a goniometer equipped with an Oxford Cryosystems cryostream maintained at a temperature of $100 \mathrm{~K}$. The wavelength used was $0.9793 \AA$ collecting 900 diffraction images at a 0.2 degree oscillation angle and 0.1 seconds exposure time on a Pilatus3 S 6M detector at a distance of $385 \mathrm{~mm}$. The diffraction data were indexed and integrated using autoPROC (Vonrhein et al., 2011)/XDS (Kabsch, 2010) and merged and scaled in AIMLESS (Evans and Murshudov, 2013) from the CCP4 suite (Winn et al., 2011). Non-isomorphous data readily yielded initial structures by molecular replacement using the Fab portion of crystal structures from the proprietary Eli Lilly structure database and the SARS-CoV2 S protein RBD from the public domain structure with the access code 6yla (Huo et al., 2020).

The initial structure coordinates were further refined using Buster (Smart et al., 2012) applying isotropic temperature factors. Model building was performed with Coot (CCP4) and final structure validation with MolProbity (Chen et al., 2010) and CCP4 validation tools.

Structure superposition with other published Fab:S complexes, contact surface analysis, and supplemental figure generation was performed with MOE (Molecular Operating Environment, 2019.0101; Chemical Computing Group ULC), and detailed contact analysis with CCP4 CONTACT(Winn et al., 2011) and custom shell/Perl scripts.

\section{Protein expression constructs}

A stabilized version of the SARS-CoV-2 S protein was employed for all studies (Hsieh 2020). The sequence corresponding to the B.1.1.7 variant extracellular domain $(E C D)$ was acquired from the GSAID database. The stabilized construct consists of the residues of the SARS-CoV2 S protein 
1-1208 with proline substitutions at position $814,889,896,939,983,984$, GSAS substitution at the furin cleavage site (679-682), C - terminal foldon trimerization domain, and an octa histidine tag. The cDNA sequence synthesized and cloned into pcDNA3.4 for mammalian cell expression (GenScript).

Fabs were generated by subcloning the variable region and $\mathrm{CH} 1$ of the heavy chain of LYCoV1404 into a pcDNA based vector with $\mathrm{C}$ terminal 6 -Histidine tag. The boundary of the $\mathrm{CH} 1$ domain was set according to the consensus sequence defining the beginning of the hinge region directly following $\mathrm{CH} 1$.

\section{Protein purification and characterization}

The plasmid encoding the B.1.1.7 stabilized S protein ECD sequence was transiently transfected into expi293 cells according to the manufacturer's specifications. Briefly, $1 \mu \mathrm{g} / \mathrm{mL}$ plasmid DNA diluted in optiMem was mixed with the recommended expifectamine/ OptiMem solution and incubated for $15 \mathrm{~min}$. The DNA/expifectamine mixture was added to expi293 cells diluted to $3 \mathrm{X} 10 \mathrm{e} 6 \mathrm{cells} / \mathrm{mL}$. After 24 hours, the recommended volumes of enhancer 1 and enhancer 2 were added to the cells, which were harvested 5 days post transfection. The supernatant was separated from the cells via centrifugation at $3000 \mathrm{Xg}$ and further clarified by passage through a 0.22 um filter. Clarified supernatants were loaded onto a $5 \mathrm{~mL} \mathrm{Ni}$ sepharose excel column (Cytiva), washed for 20 column volumes using PBS +20 mM imidazole and eluted with 10 column volumes of PBS $+500 \mathrm{mM}$ imidazole. The protein was immediately further purified using size exclusion chromatography using a superose 6 16/600 Hiload column (Cytiva). The protein was concentrated to $0.75 \mathrm{mg} / \mathrm{mL}$ (Amicon Ultra-15 $100 \mathrm{kDa}$ MWCO) and frozen in $100 \mu \mathrm{g}$ aliquots for structural Biology studies.

Fab generation was initiated with plasmids encoding the truncated heavy chain and light chain of LY-CoV1404 (1 ug/mL each) that were co-transformed into expi293 cells (expifectamine, Gibco) 
for protein expression (5 days). Cell supernatants were collected, clarified and incubated with $\mathrm{Ni}$ NTA beads to capture the Fab, followed by washing in PBS buffer ( $\mathrm{pH} 7.4$ ) and elution in the same buffer supplemented with $250 \mathrm{mM}$ Imidazole.

CryoEM sample preparation, data collection and image processing

Purified B.1.1.7 S protein $(0.8 \mathrm{mg} / \mathrm{ml})$ was mixed with LY-CoV1404 $(0.5 \mathrm{mg} / \mathrm{ml})$ and incubated on ice for 30 min. Quantifoil R 2/2, 300 mesh copper grids (Electron Microscopy Sciences) were

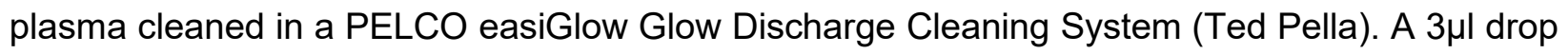
of sample was applied to freshly glow discharged grids followed by vitrification in liquid ethane using Vitrobot Mark IV with a blot time of 30 seconds. A total of 5,202 micrographs were recorded on a 3000kV Titan Krios microscope (Thermo Fisher Scientific) equipped with a Falcon IV detector at a $130,000 x$ nominal magnification corresponding to a pixel size of $0.98 \AA$. The RELION program was used for particle picking, 2D and 3D class averaging (Scheres 2016).

\section{GISAID Analysis}

To estimate the incidence of SARS-CoV-2 variants with potential resistance to LY-CoV1404, we analyzed data from GISAID EpiCoV database (Shu and McCauley, 2017), focusing on recent data, i.e. genomes collected in a 3 month window from Dec 162020 to March 16 2021, and submitted prior to March 22 2021. This gave a total of 281240 samples in the dataset, of which 76053 were from North America. We aligned the genomes to the SARS-CoV-2 reference genome (Genbank file MN908947.3) using BWA-MEM (Li and Durbin, 2010), and performed variant calling and annotation using SAMTools (Danecek et al., 2021). All further analysis (i.e. slicing by time or geographic region) was performed using custom-written Python scripts.

\section{Figure Legends}

\section{Figure 1. LY-CoV1404 discovery and binding properties.}


(A) Timeline (top) of identification of Variants of Concern (VOC) to date in the COVID-19 pandemic. Milestones of discovery of antibody therapies to treat SARS-CoV-2 infection (bottom).

(B) Representation of soluble antigen assay, live cell-based screening assay and multiplexed bead-based assay. Representative microscopic images of antibodies assessed for SARS-CoV-2 spike protein specificity in each indicated assay.

(C) Epitope binning and isolated subdomain binding for discovered antibodies and benchmarks. Each antibody was tested in two orientations: as a ligand on the chip, and as an analyte in solution. Individual antibodies are represented either as a circle (data present in both orientations) or as a square (data present with the antibody in a single orientation). Bins are represented as envelopes (46 total) and competition between antibodies as solid (symmetric competition) or dashed (asymmetric competition) lines. Benchmark-based blocking profiles are indicated by color.

(D) Single cycle kinetics of LY-CoV1404 Fab run on full-length spike protein carrying the D614G mutation.

(E) Multi-cycle kinetics of LY-CoV1404 run on indicated full length spike protein.

(F) Binding of LY-CoV1404 to indicated spike proteins expressed on CHO cells.

Figure 2. Anti-SARS-CoV-2 monoclonal antibody authentic virus neutralization

(A) Authentic virus (Italy isolate) neutralization using IFA by LY-CoV1404 and LY-CoV555 across a dose range.

(B) Authentic virus (Italy isolate) neutralization using IFA by S309 across a dose range. 
(C) Comparison of authentic virus neutralization by antibodies in PRNT and IFA assays. Specific antibodies are indicated. Data are compiled from several different individual experiments.

\section{Figure 3. Structural analysis of LY-CoV1404 binding to RBD}

(A) Three-dimensional structure of the Fab portion of LY-CoV1404 bound to the spike protein receptor-binding domain.

(B) Overlay of LY-CoV1404 compared to imdevimab (REGN10987, PDB 6DXG), bound to the spike protein receptor-binding domain.

(C) CryoEM density map of S protein-LY-CoV1404 complex shown at low threshold and docked with atomic model of S protein (cyan) and LY-CoV1404 (red) highlights binding of 3 fab molecules in 1 RBD "up" and 2 "down" conformation.

\section{Figure S1. ACE2 competition with discovered antibodies}

Competition plot of recombinantly expressed antibodies overlaid with ACE2 blocking information. ACE2 blockers and non-blockers are indicated by color (ACE2 blockers = Pink; ACE2 non-blockers $=$ orange) .

\section{Figure S2. LY-CoV1404 binding to trimeric S protein}

LY-CoV1404 modeled on 3 RBD-up (A) and 3 RBD-down (B, top; C, side) conformations of S protein. Only one molecule of LY-CoV1404 can bind to a 3-RBD-down spike trimer.

Figure S3. Antibody binding to variant B.1.351 and antibody epitopes

(A) Superposition of LY-CoV1404 (red), REGN10987 (6XDG, green), and Fab 2-7 (7LSS, yellow), with RBDs (cyan) from SARS-CoV-2 Wuhan-Hu-1 superposed on the B.1.351 variant (7NXA) (Dejnirattisai et al., 2021) showing the location of mutated sidechains.

(B) Antibody and ACE2 epitopes highlighted on the RBD sequence. 
Author contributions: B.E.J., J.D., C.C., B.A.H., D.F., J.H., V.d.P., M.W., E.L., M.R., L.D., A.O.N., R.v.d.L, P.P, H.D., F.A.G., I.L., L.A., C.P., K.D., D.K., J.A., B.S.G., J.R.M, N.K., J.J.F., S.H., I.H., L.M., H.C.P., B.R., and R.E.H. conceived of and designed experiments, data analysis and reporting, and participated in manuscript authoring and review. A.P. conceived of and designed experiments (crystallography/structure determination) and participated in manuscript authoring and review. K.S.C., P.V., L.W., E.S.Y., Y.Z., T.Z., J.M., P.D.K., N.J.S., and W.S. conceived of, designed and performed experiments/reagents (pseudovirus neutralization assay), data analysis and reporting, and participated in manuscript authoring and review. R.S. and J.C. performed yeast-display experiments to identify resistance mutations and characterized ACE2 competition for variants. T.W.G., R.W.C., D.K., and J.A. conceived of and designed experiments (PRNT assay), data analysis and reporting, and participated in manuscript review. C.C., J.D., K.E.H, and C.V.B conceived of and designed experiments (IFA assay), data analysis and reporting, and participated in manuscript review. R.G. participated in conception and design of bioinformatics experiments. data analysis and reporting. M.A.S. designed and implemented software improvements to Celium ${ }^{\mathrm{TM}}$ for antibody selection. R.G., M.A.S., K.J. and D.W.C., assisted in the acquisition, organization and interpretability of the data, and participated in manuscript review. S.Ž. and K.W. participated in design, execution, data analysis and interpretation (screening and validation experiments), as well as drafting and review of this manuscript. K.W. participated in the interpretation of screening, validation and characterization data for downselection of antibodies for expression and characterization. L.K. and Y.H. designed and executed binding kinetics \& epitope binning experiments, data analysis and reporting, and participated in manuscript authoring and review. D.P. designed and implemented data analysis and reporting pipelines for binding kinetics, epitope binning and ACE2 blocking, and participated in manuscript authoring and review. P.X. conceived experiments, designed and established the fast mutant full-length spike proteins expression vector generation protocol for cell-based validation, performed mutant tracing and surveys, and participated in manuscript authorship. P.S. participated in design of data acquisition pipeline (discovery, characterization, bioinformatics and antibody lead selection); T.L.F participated in data analysis and reporting, manuscript authorship and review. B.C.B., C.L.H. and E.F. conceived and designed experiments, analyzed and reported data (discovery, characterization, bioinformatics and antibody lead selection) and participated in manuscript authorship and review.

Acknowledgments: We would like to thank the following: Kristi Huntington (Eli Lilly and Company) and Emma McCarren (AbCellera Biologics Inc.) for project leadership and coordination; Franz Trianna, Douglas Burtrum, Prabakaran Narayanasamy, Xiaomin Yang, Ricky Lieu, Dongmei He, Henry Koo, of Eli Lilly and Company for reagent and antibody cloning, expression and purification; Craig Dickinson, Kristina Coleman and Jeffrey Boyles of Eli Lilly and Company for initiation and reagent generation for crystallography experiments; David Driver of Eli Lilly \& Company for assistance with pseudovirus genomic titering; Natalie Thornburg, Kenneth Plante, and the University of Texas Medical Branch (UTMB) World Reference Collection for Emerging Viruses and Arboviruses (WRCEVA) for the WA-1 isolate (deposited by 
N. Thornburg), San Diego isolate (deposited by N. Thornburg), the Maryland isolate (Mehul Suthar), and the Delta isolate; the SARS-CoV-2/INMI-1-Isolate/2020/Italy used in this publication was kindly provided by the European Virus Archive Goes Global project that has received funding from the European Union's Horizon 2020 research and innovation program under grant agreement no. 653316 Steven Widen of the NextGen Sequencing Core at UTMB for genomic sequencing of the variants used in this study; the SARS-CoV-2/INMI-1Isolate/2020/Italy used in this publication was kindly provided by the European Virus Archive Goes Global project that has received funding from the European Union's Horizon 2020 research and innovation program under grant agreement no. 653316; Sherie Duncan, Anders Klaus, Keith Mewis, Karine Herve, Amanda Moreira, and Emilie Lameignere of AbCellera Biologics Inc. for technical support; Chad Thiessen of AbCellera Biologics Inc. for development of features for Celium ${ }^{\mathrm{TM}}$ required for antibody selection; Clara $\mathrm{Ng}$-Cummings of AbCellera Biologics Inc. for figure generation; Wolfgang Glaesner of Eli Lilly and Company for management and personnel resources. We gratefully acknowledge the authors from the originating laboratories and the submitting laboratories, who generated and shared via GISAID genetic sequence data, on which this research is based.

Funding: Eli Lilly and Company provided resources for this study. AbCellera Biologics Inc. received funding from the U.S. Department of Defense, Defense Advanced Research Projects Agency (DARPA) - Pandemic Prevention Platform. Agreement no. D18AC00002. This research was funded in part by the U.S. Government (The views and conclusions contained in this document are those of the authors and should not be interpreted as representing the official policies, either expressed or implied, of the U.S. Government). This research used resources of the Advanced Photon Source; a U.S. Department of Energy (DOE) Office of Science User Facility operated for the DOE Office of Science by Argonne National Laboratory under Contract No. DE-AC02-06CH11357. https://www.aps.anl.gov/Science/Publications/AcknowledgmentStatement-for-Publications Use of the Lilly Research Laboratories Collaborative Access Team (LRL-CAT) beamline at Sector 31 of the Advanced Photon Source was provided by Eli Lilly \& Company, which operates the facility. http://Irlcat.lilly.com/. Intramural Program at National Institutes of Health, National Institute of Allergy and Infectious Diseases, Vaccine Research Center (to BSG, JRM). Operations support of the Galveston National Laboratory was supported by NIAID/NIH grant UC7AI094660.

Competing interests: D.F., P. V., A.P., J.H., J.M.S., R.W.S, J.C., I. H., J. J. F., S. H., H. C. P., B. R., B. A. H., R. W. S., J. C., J. M. S., R. E. H., N. K., and B.E.J. are employees and/or stockholders of Eli Lilly and Company. K.W., S. Ž., M.W., E.L., L.K., Y.H., K.J., R.G., M.A.S., D.W.C., D.P., P.X., V.d.P., R.v.d.L., M.R., L.D., C.P., I.L., L.A., P.S., T.L.F., C.L.H, E.F., and B.C.B are employees and stockholders of AbCellera Biologics Inc. AbCellera Biologics Inc. and National Institutes of Health have filed patent applications related to the work described herein (US Patent Application No. 17/192243 and International Patent Application No. PCT/US21/20843, both titled "Anti-Coronavirus Antibodies and Methods of Use"). 
Data and materials availability: All data associated with this study are available in the main text or the supplementary materials. SARS-CoV-2 viruses are being made available through the Biodefense and Emerging Infections Research Resources Repository. Antibodies for noncommercial internal research purposes can be obtained from AbCellera Biologics Inc. and/or Eli Lilly and Company under material transfer agreements. Atomic coordinates of the X-ray crystal structure of the LY-CoV1404:RBD complex have been deposited in the Protein Data Bank under accession codes 7MMO. This work is licensed under a Creative Commons Attribution 4.0 International (CC BY 4.0) license, which permits unrestricted use, distribution, and reproduction in any medium, provided the original work is properly cited. To view a copy of this license, visit https://creativecommons.org/licenses/by/4.0/. This license does not apply to figures/photos/artwork or other content included in the article that is credited to a third party; obtain authorization from the rights holder before using this material.

Disclaimer: This research was, in part, funded by the U.S. Government. The views and conclusions contained in this document are those of the authors and should not be interpreted as representing the official policies, either expressed or implied, of the U.S. Government.

Opinions, conclusions, interpretations, and recommendations are those of the authors and are not necessarily endorsed by the U.S. Army. The mention of trade names or commercial products does not constitute endorsement or recommendation for use by the Department of the Army or the Department of Defense.

This research used resources of the Advanced Photon Source, a U.S. Department of Energy (DOE) Office of Science User Facility operated for the DOE Office of Science by Argonne National Laboratory under Contract No. DE-AC02-06CH11357.

https://www.aps.anl.gov/Science/Publications/Acknowledgment-Statement-for-Publications. Use of the Lilly Research Laboratories Collaborative Access Team (LRL-CAT) beamline at Sector 31 of the Advanced Photon Source was provided by Eli Lilly \& Company, which operates the facility. http://Irlcat.lilly.com/

\section{References}

Altmann, D.M., Boyton, R.J., and Beale, R. (2021). Immunity to SARS-CoV-2 variants of concern. Science 371, 1103-1104.

Andreano, E., Nicastri, E., Paciello, I., Pileri, P., Manganaro, N., Piccini, G., Manenti, A., Pantano, E., Kabanova, A., Troisi, M., et al. (2021). Extremely potent human monoclonal antibodies from COVID-19 convalescent patients. Cell.

Aschwanden, C. (2021). Five reasons why COVID herd immunity is probably impossible. Nature 591, 520-522.

AstraZeneca (2020). COVID-19 Long-Acting AntiBody (LAAB) combination AZD7442 rapidly advances into Phase III clinical trials. Baric, R.S. (2020). Emergence of a Highly Fit SARS-CoV-2 Variant. New Engl J Med 383, 
2684-2686.

Barnes, C.O., Jette, C.A., Abernathy, M.E., Dam, K.-M.A., Esswein, S.R., Gristick, H.B., Malyutin, A.G., Sharaf, N.G., Huey-Tubman, K.E., Lee, Y.E., et al. (2020). SARS-CoV-2 neutralizing antibody structures inform therapeutic strategies. Nature 588, 682-687.

Cathcart, A.L., Havenar-Daughton, C., Lempp, F.A., Ma, D., Schmid, M., Agostini, M.L., Guarino, B., iulio, J.D., Rosen, L., Tucker, H., et al. (2021). The dual function monoclonal antibodies VIR-7831 and VIR-7832 demonstrate potent in vitro and in vivo activity against SARS-CoV-2. https://doi.org/10.1101/2021.03.09.434607

Cerutti, G., Rapp, M., Guo, Y., Bahna, F., Bimela, J., Reddem, E.R., Yu, J., Wang, P., Liu, L., Huang, Y., et al. (2021). Structural Basis for Accommodation of Emerging B.1.351 and B.1.1.7 Variants by Two Potent SARS-CoV-2 Neutralizing Antibodies. Biorxiv 2021.02.21.432168. Chen, P., Nirula, A., Heller, B., Gottlieb, R.L., Boscia, J., Morris, J., Huhn, G., Cardona, J., Mocherla, B., Stosor, V., et al. (2020). SARS-CoV-2 Neutralizing Antibody LY-CoV555 in Outpatients with Covid-19. New Engl J Med 384, 229-237.

Chen, V.B., Arendall, W.B., Headd, J.J., Keedy, D.A., Immormino, R.M., Kapral, G.J., Murray, L.W., Richardson, J.S., and Richardson, D.C. (2010). MolProbity: all-atom structure validation for macromolecular crystallography. Acta Crystallogr Sect D Biological Crystallogr 66, 12-21. Choi, B., Choudhary, M.C., Regan, J., Sparks, J.A., Padera, R.F., Qiu, X., Solomon, I.H., Kuo, H.-H., Boucau, J., Bowman, K., et al. (2020). Persistence and Evolution of SARS-CoV-2 in an Immunocompromised Host. New Engl J Med 383, 2291-2293.

Company, E.L. and (2020). Lilly's neutralizing antibody bamlanivimab (LY-CoV555) receives FDA emergency use authorization for the treatment of recently diagnosed COVID-19.

Corbett, K.S., Edwards, D.K., Leist, S.R., Abiona, O.M., Boyoglu-Barnum, S., Gillespie, R.A., Himansu, S., Schäfer, A., Ziwawo, C.T., DiPiazza, A.T., et al. (2020). SARS-CoV-2 mRNA vaccine design enabled by prototype pathogen preparedness. Nature 586, 567-571. Danecek, P., Bonfield, J.K., Liddle, J., Marshall, J., Ohan, V., Pollard, M.O., Whitwham, A., Keane, T., McCarthy, S.A., Davies, R.M., et al. (2021). Twelve years of SAMtools and BCFtools. Gigascience 10, giab008.

Darby, A.C., and Hiscox, J.A. (2021). Covid-19: variants and vaccination. Bmj 372, n771. Davies, N.G., Abbott, S., Barnard, R.C., Jarvis, C.I., Kucharski, A.J., Munday, J.D., Pearson, C.A.B., Russell, T.W., Tully, D.C., Washburne, A.D., et al. (n.d.). Estimated transmissibility and impact of SARS-CoV-2 lineage B.1.1.7 in England. MedRxiv.

Dejnirattisai, W., Zhou, D., Supasa, P., Liu, C., Mentzer, A.J., Ginn, H.M., Zhao, Y., Duyvesteyn, H.M.E., Tuekprakhon, A., Nutalai, R., et al. (2021). Antibody evasion by the P.1 strain of SARSCoV-2. Cell.

Evans, P.R., and Murshudov, G.N. (2013). How good are my data and what is the resolution? Acta Crystallogr Sect D Biological Crystallogr 69, 1204-1214.

Gottlieb, R.L., Nirula, A., Chen, P., Boscia, J., Heller, B., Morris, J., Huhn, G., Cardona, J., Mocherla, B., Stosor, V., et al. (2021). Effect of Bamlanivimab as Monotherapy or in Combination With Etesevimab on Viral Load in Patients With Mild to Moderate COVID-19. Jama 325, 632-644.

GSK (2021). Vir Biotechnology and GSK announce VIR-7831 reduces hospitalisation and risk of death in early treatment of adults with COVID-19. Gu, H., Chen, Q., Yang, G., He, L., Fan, H., Deng, Y.-Q., Wang, Y., Teng, Y., Zhao, Z., Cui, Y., 
et al. (2020). Adaptation of SARS-CoV-2 in BALB/c mice for testing vaccine efficacy. Science 369, 1603-1607.

Hansen, J., Baum, A., Pascal, K.E., Russo, V., Giordano, S., Wloga, E., Fulton, B.O., Yan, Y., Koon, K., Patel, K., et al. (2020). Studies in humanized mice and convalescent humans yield a SARS-CoV-2 antibody cocktail. Science 369, 1010-1014.

Hoffmann, M., Arora, P., Groß, R., Seidel, A., Hörnich, B.F., Hahn, A.S., Krüger, N., Graichen, L., Hofmann-Winkler, H., Kempf, A., et al. (2021). SARS-CoV-2 variants B.1.351 and P.1 escape from neutralizing antibodies. Cell. Horby, P., Huntley, C., Davies, N., Edmunds, J., Ferguson, N., Medley, G., and Semple, C. (2021). Paper from the New and Emerging Respiratory Virus Threats Advisory Group (NERVTAG) on new coronavirus (COVID-19) variant B.1.1.7.

Hsieh, C.-L., Goldsmith, J.A., Schaub, J.M., DiVenere, A.M., Kuo, H.-C., Javanmardi, K., Le, K.C., Wrapp, D., Lee, A.G., Liu, Y., et al. (2020). Structure-based design of prefusion-stabilized SARS-CoV-2 spikes. Science 369, 1501-1505.

Huo, J., Bas, A.L., Ruza, R.R., Duyvesteyn, H.M.E., Mikolajek, H., Malinauskas, T., Tan, T.K., Rijal, P., Dumoux, M., Ward, P.N., et al. (2020). Neutralizing nanobodies bind SARS-CoV-2 spike RBD and block interaction with ACE2. Nat Struct Mol Biol 27, 846-854. Jiang, S., Zhang, X., Yang, Y., Hotez, P.J., and Du, L. (2020). Neutralizing antibodies for the treatment of COVID-19. Nat Biomed Eng 4, 1134-1139.

Jones, B.E., Brown-Augsburger, P.L., Corbett, K.S., Westendorf, K., Davies, J., Cujec, T.P., Wiethoff, C.M., Blackbourne, J.L., Heinz, B.A., Foster, D., et al. (2020). LY-CoV555, a rapidly isolated potent neutralizing antibody, provides protection in a non-human primate model of SARS-CoV-2 infection. Biorxiv 2020.09.30.318972. Jones, B.E., Brown-Augsburger, P.L., Corbett, K.S., Westendorf, K., Davies, J., Cujec, T.P., Wiethoff, C.M., Blackbourne, J.L., Heinz, B.A., Foster, D., et al. (2021). The neutralizing antibody, LY-CoV555, protects against SARS-CoV-2 infection in non-human primates. Sci Transl Med eabf1906.

Kabsch, W. (2010). XDS. Acta Crystallogr Sect D Biological Crystallogr 66, 125-132. Kemp, S.A., Collier, D.A., Datir, R.P., Ferreira, I.A.T.M., Gayed, S., Jahun, A., Hosmillo, M., Rees-Spear, C., Mlcochova, P., Lumb, I.U., et al. (2021). SARS-CoV-2 evolution during treatment of chronic infection. Nature 1-10.

Kuzmina, A., Khalaila, Y., Voloshin, O., Keren-Naus, A., Bohehm, L., Raviv, Y., Shemer-Avni, Y., Rosenberg, E., and Taube, R. (2021). SARS CoV-2 spike variants exhibit differential infectivity and neutralization resistance to convalescent or post-vaccination sera. Cell Host Microbe. Li, H., and Durbin, R. (2010). Fast and accurate long-read alignment with Burrows-Wheeler transform. Bioinformatics 26, 589-595. Lieu, R., Antonysamy, S., Druzina, Z., Ho, C., Kang, R., Pustilnik, A., Wang, J., and Atwell, S. (2020a). Rapid and robust antibody Fab fragment crystallization utilizing edge-to-edge betasheet packing. Biorxiv 2020.04.14.040949.

Lieu, R., Antonysamy, S., Druzina, Z., Ho, C., Kang, N.R., Pustilnik, A., Wang, J., and Atwell, S. (2020b). Rapid and robust antibody Fab fragment crystallization utilizing edge-to-edge betasheet packing. Plos One 15, e0232311. Liu, L., Wang, P., Nair, M.S., Yu, J., Rapp, M., Wang, Q., Luo, Y., Chan, J.F.-W., Sahi, V., 
Figueroa, A., et al. (2020). Potent neutralizing antibodies against multiple epitopes on SARSCoV-2 spike. Nature 584, 450-456.

Liu, Z., VanBlargan, L.A., Bloyet, L.-M., Rothlauf, P.W., Chen, R.E., Stumpf, S., Zhao, H., Errico, J.M., Theel, E.S., Liebeskind, M.J., et al. (2021). Identification of SARS-CoV-2 spike mutations that attenuate monoclonal and serum antibody neutralization. Cell Host Microbe 29, 477-488.e4.

Mansbach, R.A., Chakraborty, S., Nguyen, K., Montefiori, D.C., Korber, B., and Gnanakaran, S. (2020). The SARS-CoV-2 Spike Variant D614G Favors an Open Conformational State. Biorxiv 2020.07.26.219741.

McCormick, K.D., Jacobs, J.L., and Mellors, J.W. (2021). The emerging plasticity of SARS-CoV2. Science 371, 1306-1308.

Medicine, U.S.N.L. of (2020). A Study of Immune System Proteins in Participants With Mild to Moderate COVID-19 IIIness (BLAZE-4).

Mercatelli, D., and Giorgi, F.M. (2020). Geographic and Genomic Distribution of SARS-CoV-2 Mutations. Front Microbiol 11, 1800.

Munnink, B.B.O., Sikkema, R.S., Nieuwenhuijse, D.F., Molenaar, R.J., Munger, E., Molenkamp, R., Spek, A. van der, Tolsma, P., Rietveld, A., Brouwer, M., et al. (2021). Transmission of SARS-CoV-2 on mink farms between humans and mink and back to humans. Science 371 , $\underline{172-177 .}$

Naldini, L., Blömer, U., Gage, F.H., Trono, D., and Verma, I.M. (1996). Efficient transfer, integration, and sustained long-term expression of the transgene in adult rat brains injected with a lentiviral vector. Proc National Acad Sci 93, 11382-11388.

Nie, J., Li, Q., Wu, J., Zhao, C., Hao, H., Liu, H., Zhang, L., Nie, L., Qin, H., Wang, M., et al. (2020). Establishment and validation of a pseudovirus neutralization assay for SARS-CoV-2. Emerg Microbes Infec 9, 680-686.

Pachetti, M., Marini, B., Benedetti, F., Giudici, F., Mauro, E., Storici, P., Masciovecchio, C., Angeletti, S., Ciccozzi, M., Gallo, R.C., et al. (2020). Emerging SARS-CoV-2 mutation hot spots include a novel RNA-dependent-RNA polymerase variant. J Transl Med 18, 179.

Pinto, D., Park, Y.-J., Beltramello, M., Walls, A.C., Tortorici, M.A., Bianchi, S., Jaconi, S., Culap, K., Zatta, F., Marco, A.D., et al. (2020). Cross-neutralization of SARS-CoV-2 by a human monoclonal SARS-CoV antibody. Nature 583, 290-295.

Plante, J.A., Liu, Y., Liu, J., Xia, H., Johnson, B.A., Lokugamage, K.G., Zhang, X., Muruato, A.E., Zou, J., Fontes-Garfias, C.R., et al. (2020). Spike mutation D614G alters SARS-CoV-2 fitness. Nature 1-6.

Rappazzo, C.G., Tse, L.V., Kaku, C.I., Wrapp, D., Sakharkar, M., Huang, D., Deveau, L.M., Yockachonis, T.J., Herbert, A.S., Battles, M.B., et al. (2021). Broad and potent activity against SARS-like viruses by an engineered human monoclonal antibody. Science 371, 823-829. Rees-Spear, C., Muir, L., Griffith, S.A., Heaney, J., Aldon, Y., Snitselaar, J.L., Thomas, P., Graham, C., Seow, J., Lee, N., et al. (2021). The impact of Spike mutations on SARS-CoV-2 neutralization. Cell Reports 34, 108890.

Regeneron (2021). Phase 3 Trial Shows REGEN-COV тм (Casirivimab With Imdevimab) Antibody Cocktail Reduced Hospitalization or Death by $70 \%$ in Non-Hospitalized COVID-19 Patients. Santos, J.C., and Passos, G.A. (2021). The high infectivity of SARS-CoV-2 B.1.1.7 is associated with increased interaction force between Spike-ACE2 caused by the viral N501Y 
mutation. Biorxiv 2020.12.29.424708.

Scheres, S.H.W. (2016). Chapter Six Processing of Structurally Heterogeneous Cryo-EM Data in RELION. Methods Enzymol 579, 125-157.

Shu, Y., and McCauley, J. (2017). GISAID: Global initiative on sharing all influenza data - from vision to reality. Eurosurveillance 22, 30494.

Smart, O.S., Womack, T.O., Flensburg, C., Keller, P., Paciorek, W., Sharff, A., Vonrhein, C., and Bricogne, G. (2012). Exploiting structure similarity in refinement: automated NCS and target-structure restraints in BUSTER. Acta Crystallogr Sect D Biological Crystallogr 68, 368$\underline{380}$.

Tegally, H., Wilkinson, E., Lessells, R.J., Giandhari, J., Pillay, S., Msomi, N., Mlisana, K., Bhiman, J.N., Gottberg, A. von, Walaza, S., et al. (2021). Sixteen novel lineages of SARS-CoV2 in South Africa. Nat Med 27, 440-446.

Thomson, E.C., Rosen, L.E., Shepherd, J.G., Spreafico, R., Filipe, A. da S., Wojcechowskyi. J.A., Davis, C., Piccoli, L., Pascall, D.J., Dillen, J., et al. (2021). Circulating SARS-CoV-2 spike N439K variants maintain fitness while evading antibody-mediated immunity. Cell 184, 11711187.e20.

Tortorici, M.A., Czudnochowski, N., Starr, T.N., Marzi, R., Walls, A.C., Zatta, F., Bowen, J.E., Jaconi, S., iulio, J. di, Wang, Z., et al. (2021). Structural basis for broad sarbecovirus neutralization by a human monoclonal antibody. Biorxiv Prepr Serv Biology.

Vonrhein, C., Flensburg, C., Keller, P., Sharff, A., Smart, O., Paciorek, W., Womack, T., and Bricogne, G. (2011). Data processing and analysis with the autoPROC toolbox. Acta Crystallogr Sect D Biological Crystallogr 67, 293-302.

Wang, L., Zhou, T., Zhang, Y., Yang, E.S., Schramm, C.A., Shi, W., Pegu, A., Oloninyi, O.K., Ransier, A., Darko, S., et al. (2021a). Antibodies with potent and broad neutralizing activity against antigenically diverse and highly transmissible SARS-CoV-2 variants. Biorxiv 2021.02.25.432969.

Wang, P., Nair, M.S., Liu, L., Iketani, S., Luo, Y., Guo, Y., Wang, M., Yu, J., Zhang, B., Kwong, P.D., et al. (2021b). Antibody Resistance of SARS-CoV-2 Variants B.1.351 and B.1.1.7. Nature $1-9$.

Whitt, M.A. (2010). Generation of VSV pseudotypes using recombinant $\Delta G-V S V$ for studies on virus entry, identification of entry inhibitors, and immune responses to vaccines. J Virol Methods 169, 365-374.

WHO (2021). COVID-19 Weekly Epidemiological Update (World Health Organization).

Winn, M.D., Ballard, C.C., Cowtan, K.D., Dodson, E.J., Emsley, P., Evans, P.R., Keegan, R.M., Krissinel, E.B., Leslie, A.G.W., McCoy, A., et al. (2011). Overview of the CCP4 suite and current developments. Acta Crystallogr Sect D Biological Crystallogr 67, 235-242.

Xie, X., Liu, Y., Liu, J., Zhang, X., Zou, J., Fontes-Garfias, C.R., Xia, H., Swanson, K.A., Cutler, M., Cooper, D., et al. (2021a). Neutralization of SARS-CoV-2 spike 69/70 deletion, E484K and N501Y variants by BNT162b2 vaccine-elicited sera. Nat Med 1-2.

Xie, X., Lokugamage, K.G., Zhang, X., Vu, M.N., Muruato, A.E., Menachery, V.D., and Shi, P.Y. (2021b). Engineering SARS-CoV-2 using a reverse genetic system. Nat Protoc 16, 17611784.

Yao, W., Wang, Y., Ma, D., Tang, X., Wang, H., Li, C., Lin, H., Li, Y., and Zhong, G. (2021). Spike mutations decrease SARS-CoV-2 sensitivity to neutralizing antibodies but not ACE2-Ig in 
bioRxiv preprint doi: https://doi.org/10.1101/2021.04.30.442182; this version posted January 7, 2022. The copyright holder for this preprint (which was not certified by peer review) is the author/funder. All rights reserved. No reuse allowed without permission.

vitro. Biorxiv 2021.01.27.428353. Yurkovetskiy, L., Wang, X., Pascal, K.E., Tomkins-Tinch, C., Nyalile, T., Wang, Y., Baum, A., Diehl, W.E., Dauphin, A., Carbone, C., et al. (2020). Structural and Functional Analysis of the D614G SARS-CoV-2 Spike Protein Variant. Biorxiv 2020.07.04.187757. 
Fig 1A. Discovery Timeline

\begin{tabular}{|c|c|c|c|c|c|c|}
\hline $\begin{array}{l}\text { Variant } \\
\text { Emergences }\end{array}$ & $\begin{array}{l}\text { SARS-C } \\
\text { first identif }\end{array}$ & & $\begin{array}{l}\text { D614C } \\
\text { first des }\end{array}$ & $\begin{array}{l}\text { tation } \\
\text { ed }\end{array}$ & $\begin{array}{l}\text { B.1.4 } \\
\text { variant }\end{array}$ & $\begin{array}{l}\text { B.1.42 } \\
\text { tified }\end{array}$ \\
\hline Timeline & JAN 2020 & FEB & MAR & APR & MAY & JUN \\
\hline \multirow[t]{2}{*}{$\begin{array}{l}\text { Discovery } \\
\text { Milestones }\end{array}$} & \multicolumn{3}{|c|}{$\begin{array}{l}\text { Antibody discovery effort from } \\
\text { convalescent patient sample, } \\
20 \text { days from symptom onset }\end{array}$} & \multicolumn{3}{|c|}{$\begin{array}{l}\text { Antibody discovery effort from } \\
\text { convalescent patient sample, } \\
60 \text { days from symptom onset }\end{array}$} \\
\hline & \multicolumn{3}{|c|}{$\begin{array}{l}\text { LY-CoV555 (bamlanivimab) } \\
\text { identified from this effort }\end{array}$} & \multicolumn{3}{|c|}{$\begin{array}{l}\text { LY-CoV1404 identified } \\
\text { from this effort }\end{array}$} \\
\hline
\end{tabular}

\begin{tabular}{|c|c|c|c|c|c|c|}
\hline $\begin{array}{l}\mathrm{D} 614 \mathrm{G} \text { is } \\
\text { the dominant } \\
\text { variant globally }\end{array}$ & $\begin{array}{l}\text { B.1.1.7 } \\
\text { variant } \\
\text { identified } \\
\end{array}$ & $\begin{array}{l}\text { B.1.351 } \\
\text { variant } \\
\text { identified } \\
\\
\downarrow\end{array}$ & \multicolumn{2}{|c|}{$\begin{array}{l}\text { B.1.526 } \\
\text { variant } \\
\text { identified } \\
\end{array}$} & \multicolumn{2}{|c|}{$\begin{array}{l}\text { P.1 variant } \\
\text { identified }\end{array}$} \\
\hline AUG & SEP & OCT & NOV & DEC & JAN & FEB 2021 \\
\hline & & $\begin{array}{l}\text { amlanivi } \\
\text { eceives FD }\end{array}$ & $\mathrm{EUA}^{1}$ & $\begin{array}{l}\text { Viral } \\
\text { mutant } \\
\text { of LY-C }\end{array}$ & & $\begin{array}{l}\text { CoV1404 } \\
\text { lufacturing }\end{array}$ \\
\hline
\end{tabular}


Fig 1B. Single B Cell Screening Strategy
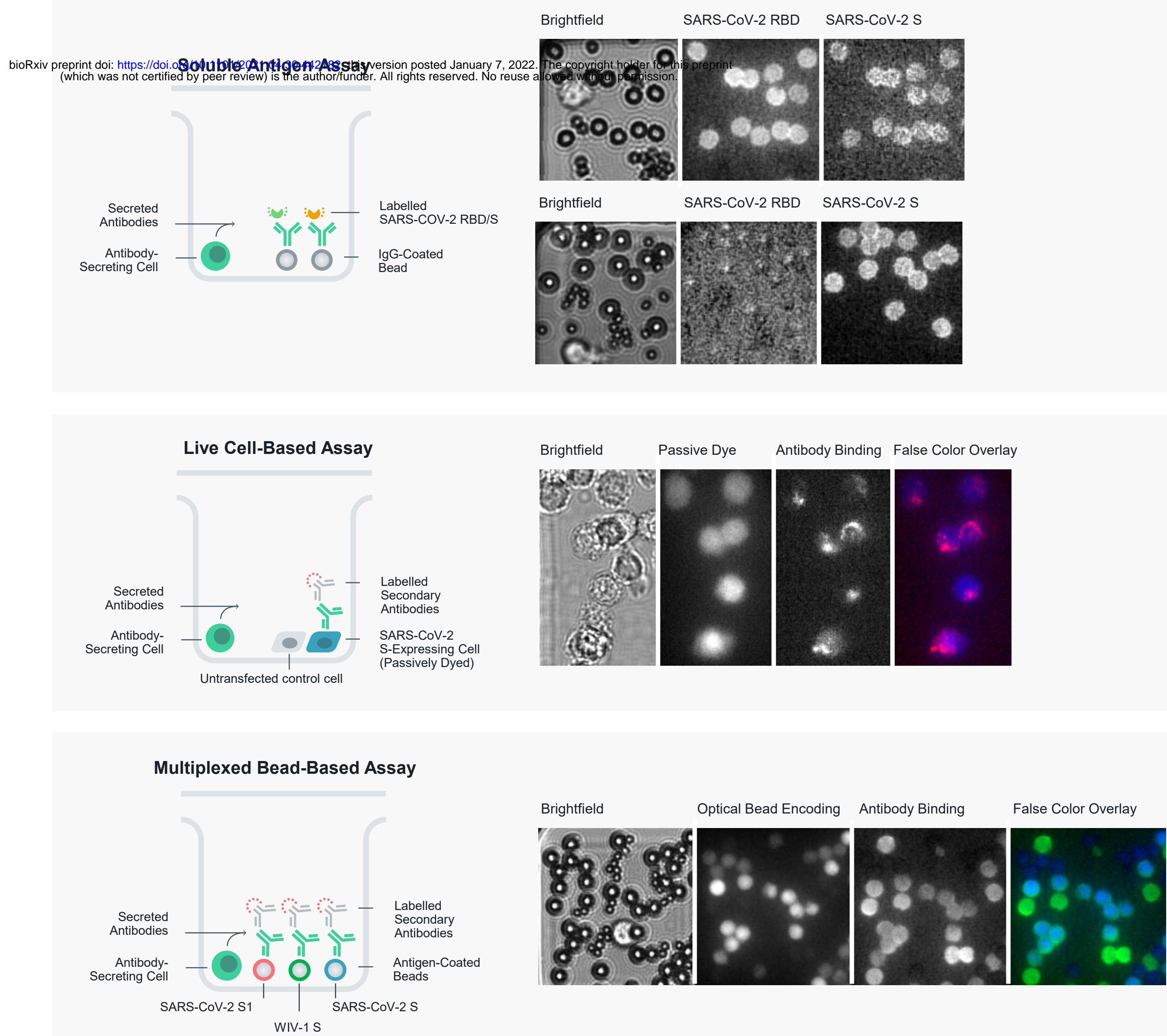
Fig 1C. Antibody Binning

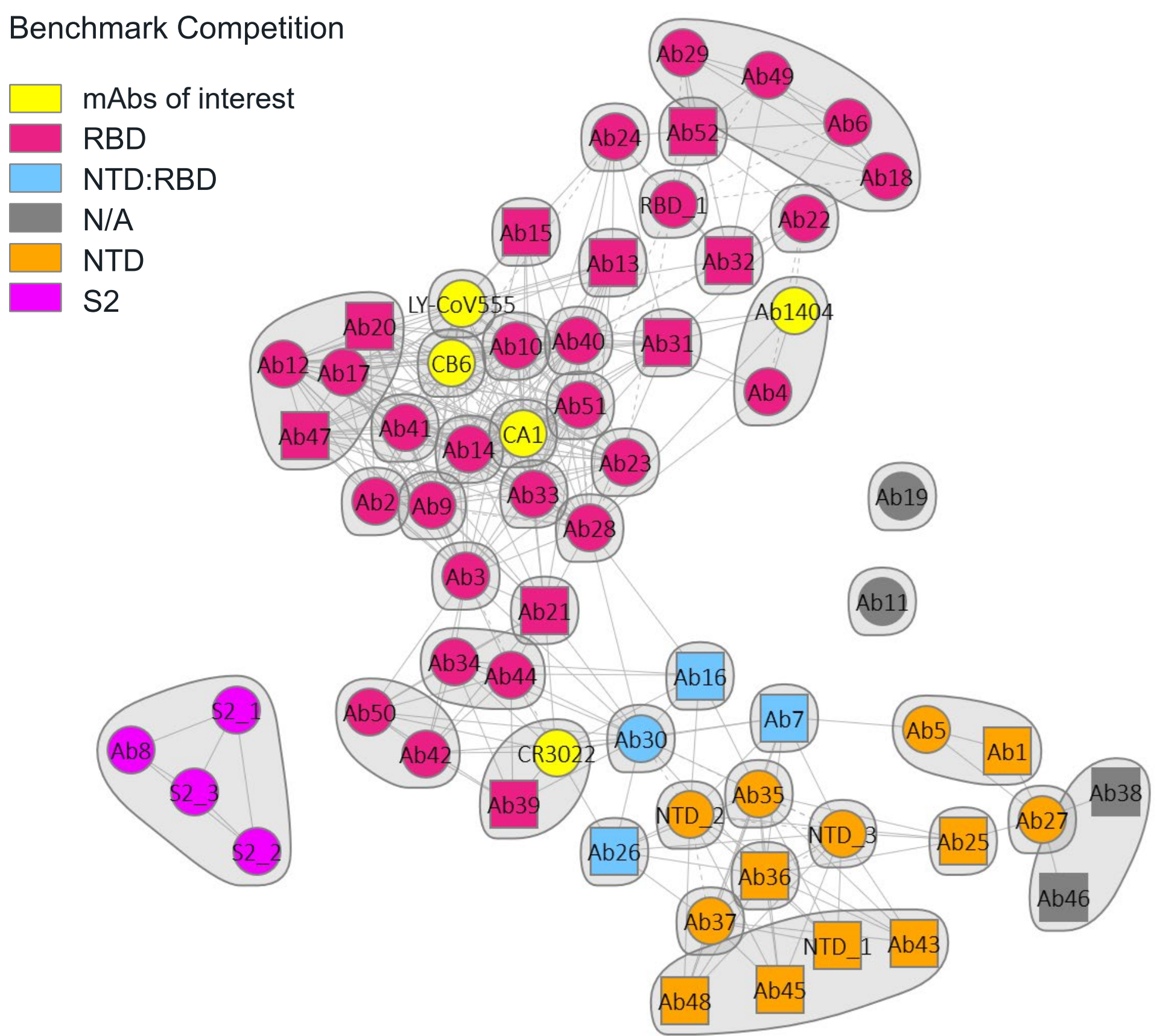


Fig 1D. Single Cycle Kinetics: LY-CoV1404 Fab binding to D614G FL Spike

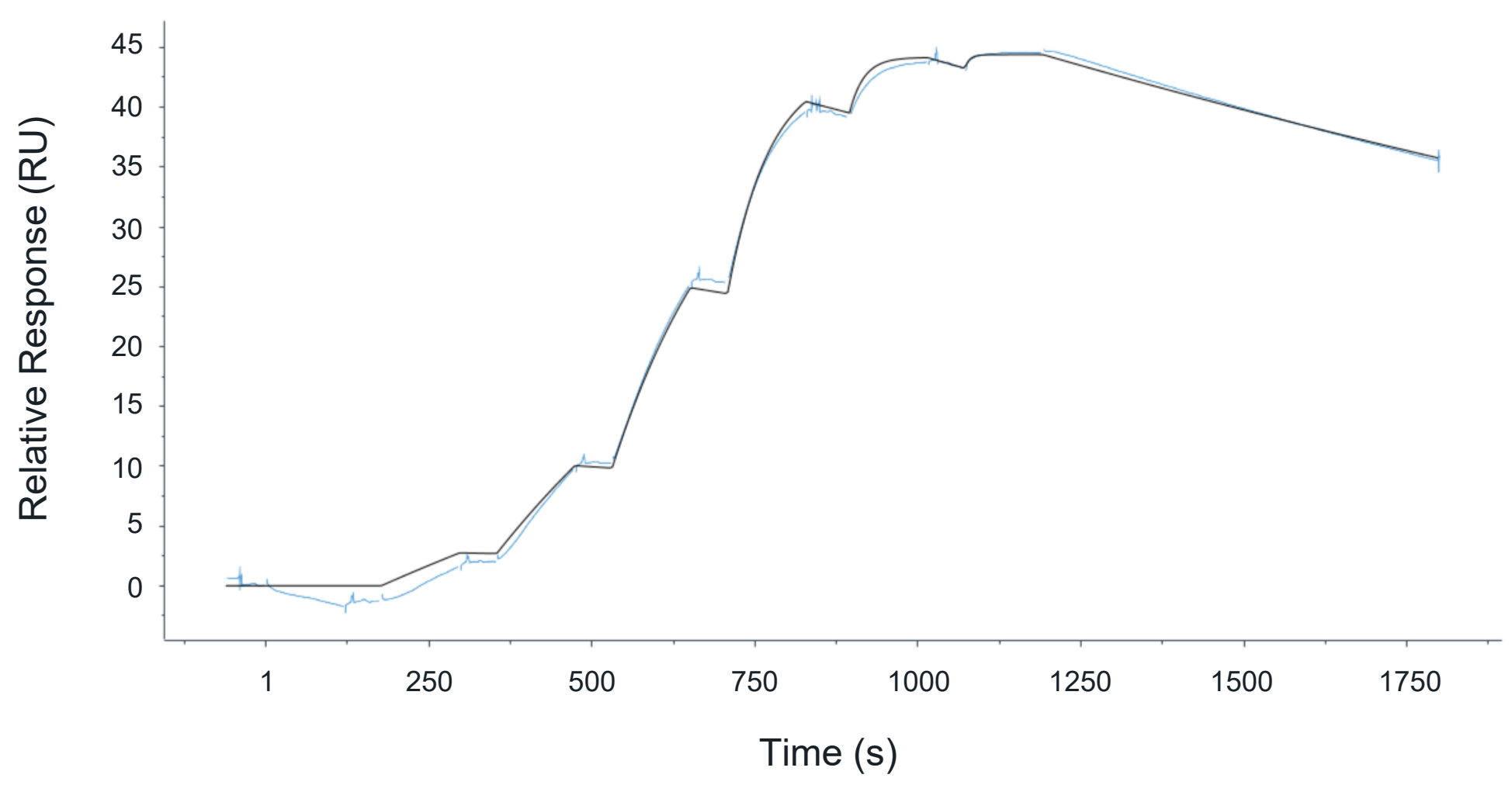

$K D(M)=7.9 e-10 M$

$\mathrm{Ka}\left(\mathrm{M}^{-1} \mathbf{s}^{-1}\right)=4.52 \mathrm{e}+05$

$\operatorname{Kd}\left(\mathbf{s}^{-1}\right)=3.57 \mathrm{e}-04$ 
Fig 1E. Multi Cycle Kinetics: LY-CoV1404 Binding to Various FL Spikes (1:1 Binding)
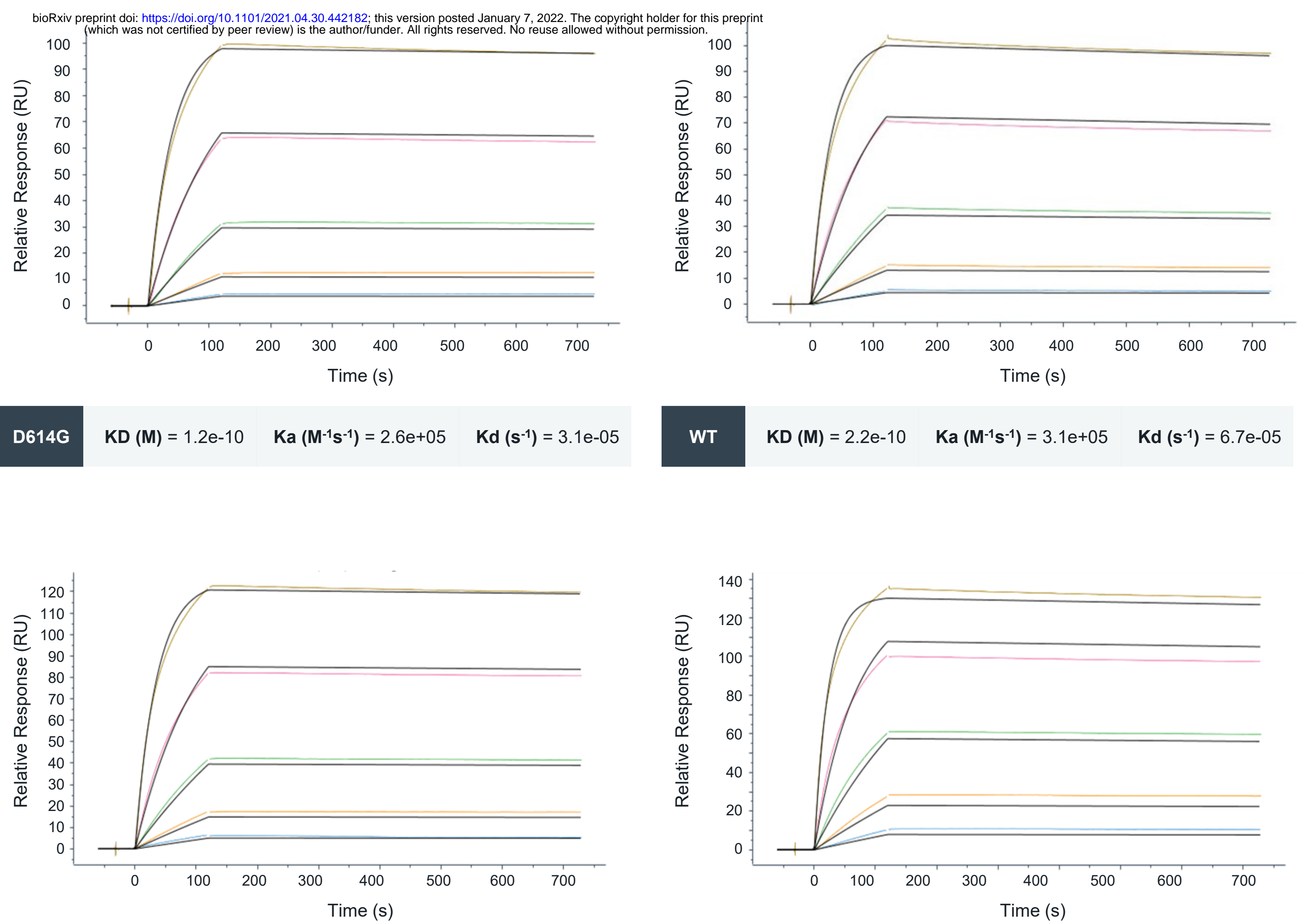
Fig 1F. LY-CoV1404 Binds to Spike Protein Mutants

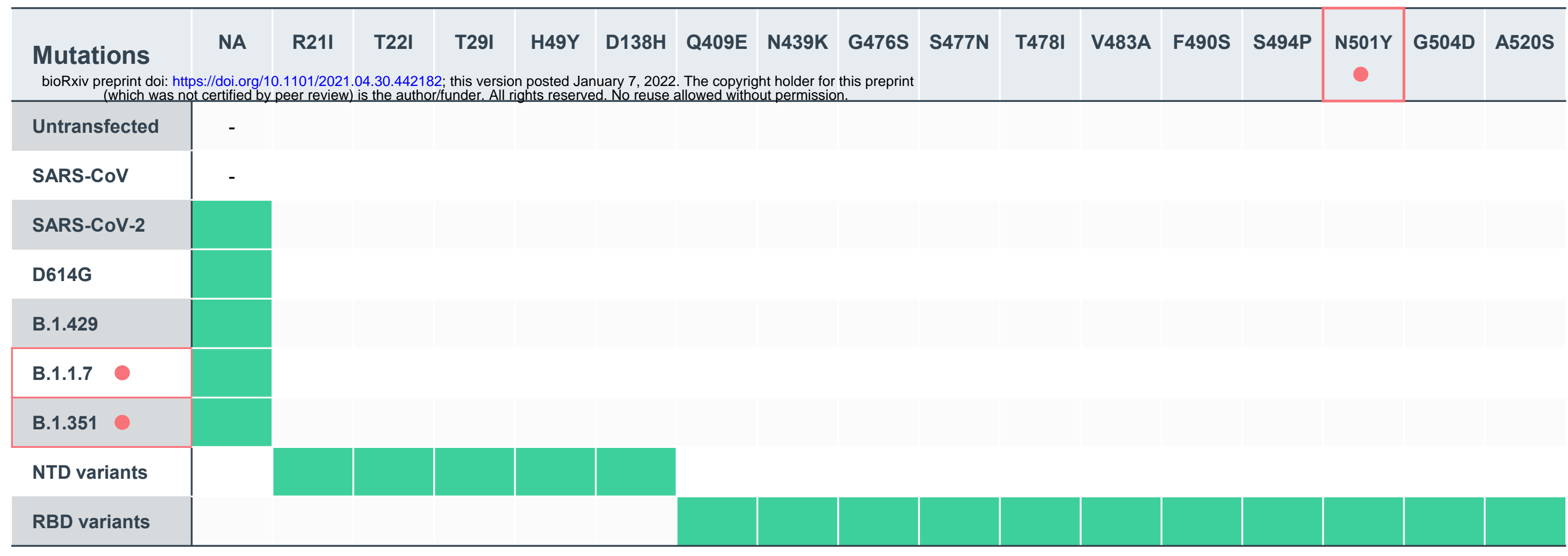

(Continued)

\begin{tabular}{|c|c|c|c|c|c|c|c|c|c|c|c|c|c|c|c|c|}
\hline Mutations & D80Y & A222V & L18F & K417T & R457K & K462N & E484G & N501S & E484K & N501T & E484Q & E484D & E484A & N501H & $\begin{array}{c}\text { N501I } \\
\end{array}$ & L452R \\
\hline \multicolumn{17}{|l|}{ NTD variants } \\
\hline \multicolumn{17}{|l|}{ RBD variants } \\
\hline RBM variants & & & & & & & & & & & & & & & & \\
\hline
\end{tabular}


bioRxiv preprint doi: https://doi.org/10.1101/2021.04.30.442182; this version posted January 7, 2022. The copyright holder for this preprint (which was not certified by peer review) is the author/funder. All rights reserved. No reuse allowed without permission.

Table 1. Summary of Target-Binding Affinities Measured through Surface Plasmon Resonance

\begin{tabular}{|l|l|l|}
\hline Antibody & Protein Studied & Affinity $\left(\mathrm{K}_{\mathrm{D}}\right), 25^{\circ} \mathrm{C}$ \\
\hline Full-length mAb & Trimeric spike protein & $7.45 \times 10^{-11} \mathrm{M}(\mathrm{n}=3)$ \\
\hline Full-length mAb & Trimeric D614G spike protein & $4.61 \times 10^{-11} \mathrm{M}(\mathrm{n}=3)$ \\
\hline Full-length mAb & Receptor-binding domain (monomeric) & $1.58 \times 10^{-9} \mathrm{M}(\mathrm{n}=2)$ \\
\hline Fab portion & Receptor-binding domain & $4.01 \times 10^{-9} \mathrm{M}(\mathrm{n}=16)$ \\
\hline
\end{tabular}

Abbreviations

$\mathrm{Fab}=$ fragment antigen binding; $\mathbf{m A b}=$ monoclonal antibody $; \mathbf{n}=$ number 
Table 2. Neutralization of Virus Infectivity by Plaque Reduction Assay

\begin{tabular}{|c|c|c|}
\hline & $\begin{array}{c}\mathrm{IC}_{50}, \mu \mathrm{g} / \mathrm{mL} \\
(95 \% \mathrm{Cl})\end{array}$ & $\begin{array}{l}\mathrm{IC}_{90,} \mu \mathrm{g} / \mathrm{mL} \\
(95 \% \mathrm{Cl})\end{array}$ \\
\hline \multicolumn{3}{|c|}{ 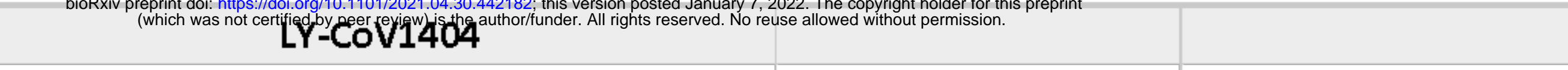 } \\
\hline WA isolate & $\begin{array}{c}0.002 \\
(0.002,0.004)\end{array}$ & $\begin{array}{c}0.0017 \\
(0.007,0.044)\end{array}$ \\
\hline |taly-INMI1 & $\begin{array}{c}0.010 \\
(0.008,0.012)\end{array}$ & $\begin{array}{c}0.142 \\
(0.085,0.239)\end{array}$ \\
\hline Netherlands & $\begin{array}{c}0.005 \\
0.004,0.006)\end{array}$ & $\begin{array}{c}0.038 \\
(0.022,0.066)\end{array}$ \\
\hline \multicolumn{3}{|c|}{ mAb combinations (molar ratio)* } \\
\hline LY-CoV1404 & $\begin{array}{c}0.015 \\
(0.012,0.018)\end{array}$ & $\begin{array}{c}0.066 \\
(0.038,0.114)\end{array}$ \\
\hline Bamlanivimab & $\begin{array}{c}0.031 \\
(0.024,0.041)\end{array}$ & $\begin{array}{c}0.134 \\
(0.074,0.242)\end{array}$ \\
\hline Etesevimab & $\begin{array}{c}0.189 \\
(0.069,0.519)\end{array}$ & $\begin{array}{c}2.633 \\
(0.446,15.529)\end{array}$ \\
\hline LY-CoV1404 + Bamlanivimab (1:2) & $\begin{array}{c}0.030 \\
(0.024,0.037)\end{array}$ & $\begin{array}{c}0.128 \\
(0.080,0.206)\end{array}$ \\
\hline LY-CoV1404 + Etesevimab (1:4) & $\begin{array}{c}0.049 \\
(0.041,0.058)\end{array}$ & $\begin{array}{c}0.185 \\
(0.128,0.267)\end{array}$ \\
\hline $\begin{array}{c}\text { LY-CoV1404 + Bamlanivimab + } \\
\text { Etesevimab }(1: 2: 4)\end{array}$ & $\begin{array}{c}0.023 \\
(0.018,0.030)\end{array}$ & $\begin{array}{c}0.140 \\
(0.076,0.258)\end{array}$ \\
\hline
\end{tabular}


Table 3A. Live virus Neutralization of SARS-CoV-2 Variants in the Presence of LY-CoV1404 (PRNT assay)

bioRxiv preprint doi: https://doi.org/10.1101/2021.04.30.442182; this version posted January 7, 2022. The copyright holder for this preprint

(which was not certified by peer review) is the author/funder. All rights reserved. No reuse allowed without permission.

\begin{tabular}{|c|c|c|c|}
\hline SARS-CoV-2 Variant & Viral Isolate & $\begin{array}{l}\text { IC50 } \\
\mu g / m L^{b}\end{array}$ & $\begin{array}{l}\text { IC90 } \\
\mu g / \mathrm{mL}^{\mathrm{b}}\end{array}$ \\
\hline Wuhan & USA/WA/1/2020a & 0.011 & 0.108 \\
\hline Alpha / B.1.1.7 / UK Origin & $\begin{array}{l}\text { England/204820464/2 } \\
020\end{array}$ & 0.004 & 0.044 \\
\hline $\begin{array}{l}\text { Beta / B.1.351 / South } \\
\text { Africa Origin }\end{array}$ & $\begin{array}{l}\text { USA/MD- } \\
\text { HP01542/2021 }\end{array}$ & 0.007 & 0.045 \\
\hline rWT controlc & $\begin{array}{l}\text { Reverse genetics } \\
\text { recombinant virus }\end{array}$ & 0.015 & 0.056 \\
\hline rWA1 + E484K & $\begin{array}{l}\text { Reverse genetics } \\
\text { recombinant virus } \\
\text { containing E484K }\end{array}$ & 0.010 & 0.047 \\
\hline rWA1 + E484Q & $\begin{array}{l}\text { Reverse genetics } \\
\text { recombinant virus } \\
\text { containing } E 484 Q\end{array}$ & 0.014 & 0.067 \\
\hline
\end{tabular}

\section{Abbreviations}

$\mathbf{C I}=$ confidence interval. $\mathbf{I C 5 0}=$ concentration inhibiting maximal activity by $50 \%$; IC90 = concentration inhibiting maximal activity by $90 \%$; nc $=$ no change (difference was less than $\leq 5$-fold); SARS-CoV-2 = severe acute respiratory syndrome coronavirus 2 . a SARS-CoV-2 S GenBank MN908947.3.

b IC50 values presented are geometric mean if multiple experiments were performed and a weighted geometric mean for the Wuhan strain $(n=X) .95 \% \mathrm{Cl}$ values were included for variants tested only once.

c Recombinant constructed virus 
Table 3B. LY-CoV1404 potently neutralizes SARS-CoV-2 variants

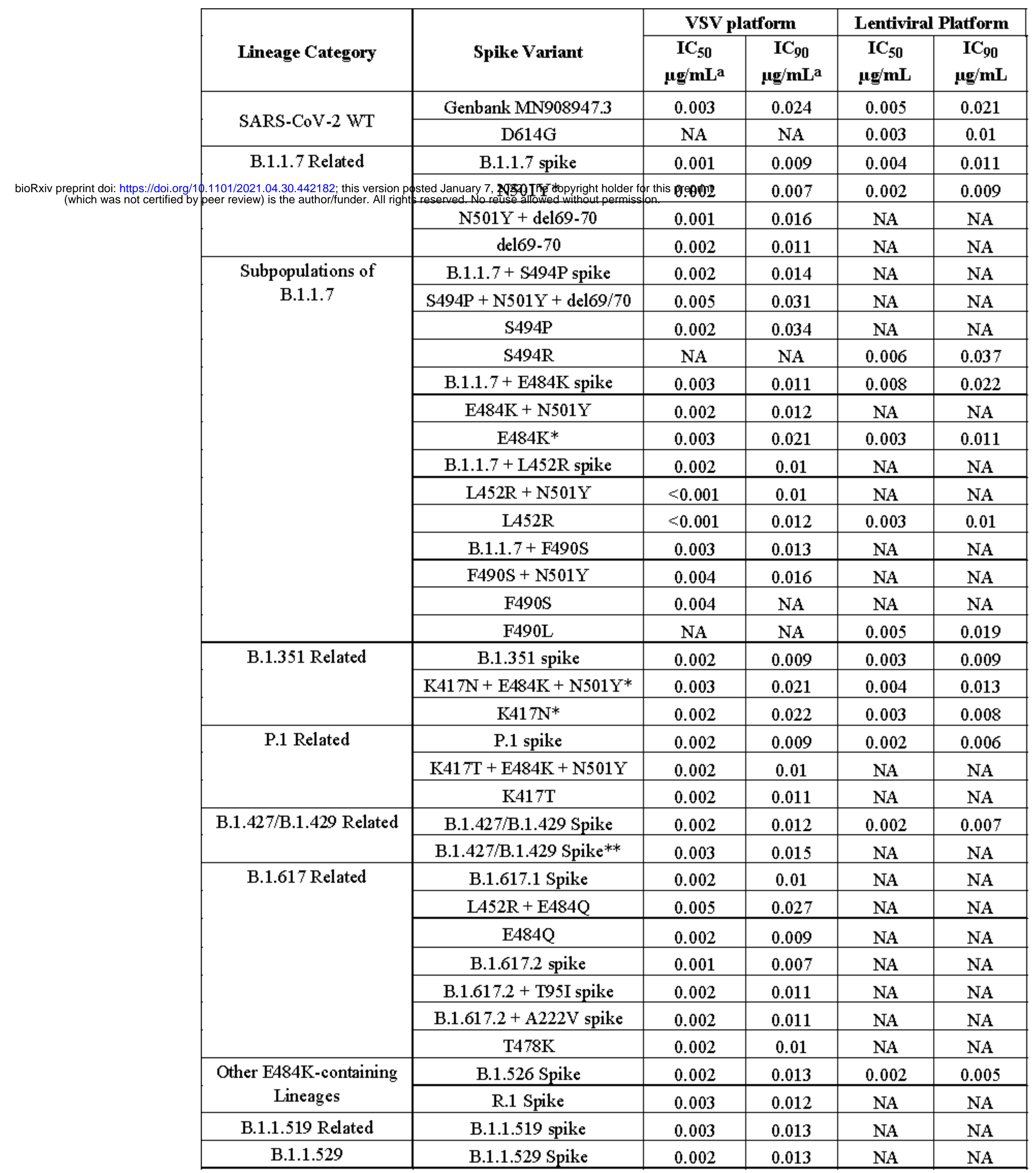


Table 3B. (continued)

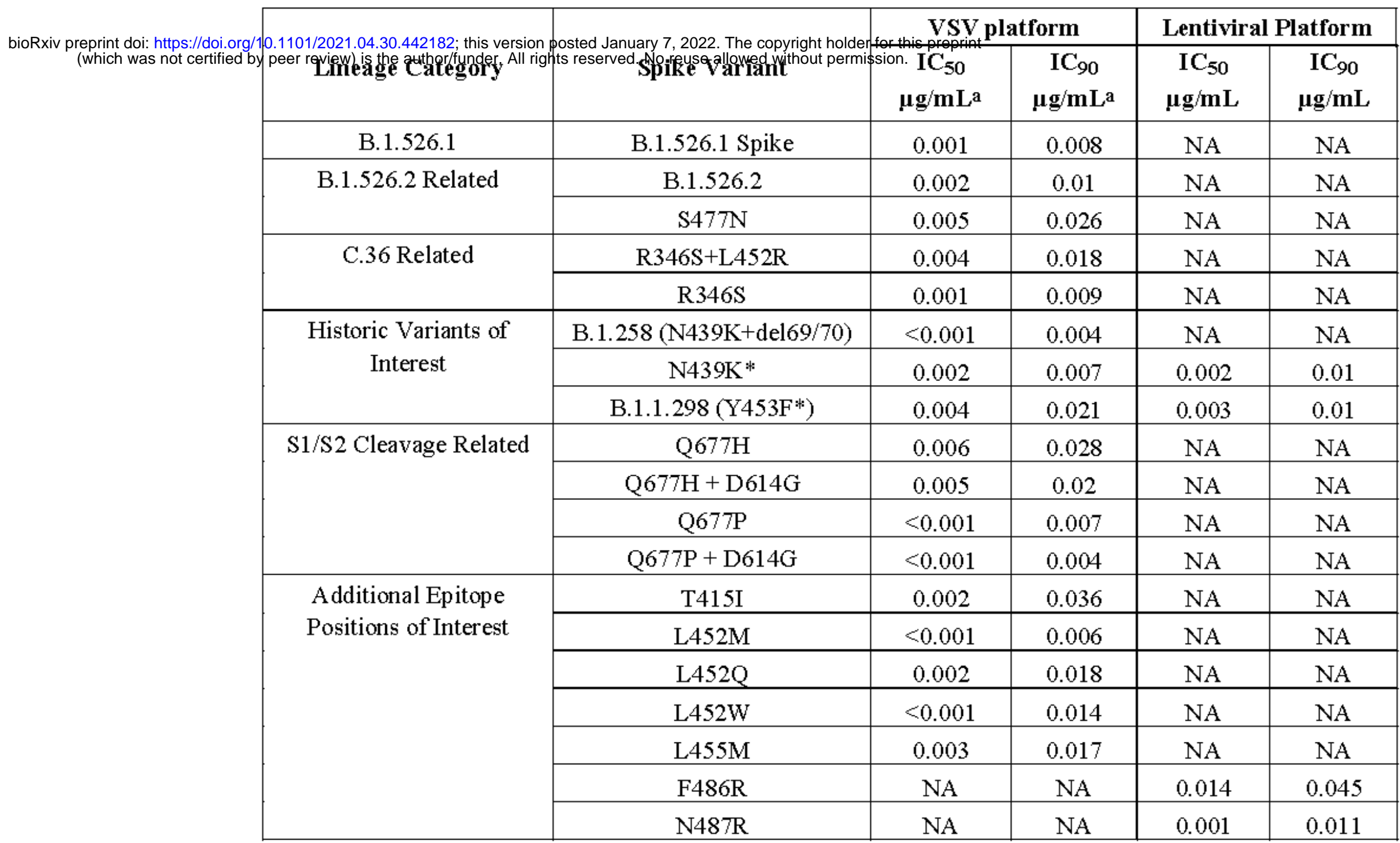

Abbreviations: $\mathrm{D}=$ aspartate; del = deletion; $\mathrm{E}=$ glutamate; $\mathrm{G}=$ glycine; $\mathrm{H}=$ histidine; $\mathrm{I}=$ isoleucine; $\mathrm{IC}_{50}, \mathrm{IC}_{90}=$ concentration inhibiting maximal activity by $50 \%$ and $90 \%$, respectively; $\mathrm{K}=$ lysine; $\mathrm{L}=$ leucine; $\mathrm{N}=$ asparagine; $\mathrm{NA}=$ not applicable; $\mathrm{P}=$ proline; $\mathrm{Q}=$ glutamine $\mathrm{R}=$ arginine; $\mathrm{S}=$ serine; $\mathrm{T}=$ threonine; $\mathrm{Y}=$ tyrosine.

a Absolute IC estimates presented are a result of a meta-analysis of multiple replicate experiments.

* Viral constructs for the lentivural platform include D614G

*** Viral constructs for the VSV platform include D614G 
Table 3C. Neutralization Activity of Class III Monoclonal Antibodies Against SARS-CoV-2 on B.1.1.529

\begin{tabular}{|c|c|c|c|c|c|c|c|}
\hline \multirow{3}{*}{$\begin{array}{l}\text { Source } \\
\text { pioRxiv preprind } \\
\text { (which was not certit|/dd }\end{array}$} & \multirow{3}{*}{ 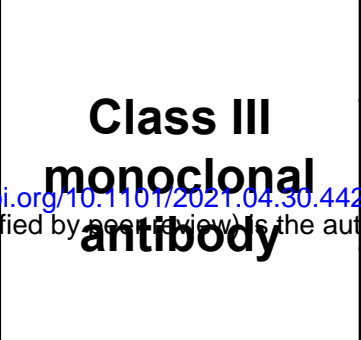 } & \multicolumn{4}{|c|}{ SARS-CoV-2 variant } & \multicolumn{2}{|c|}{ D614G* } \\
\hline & & \multicolumn{2}{|c|}{ 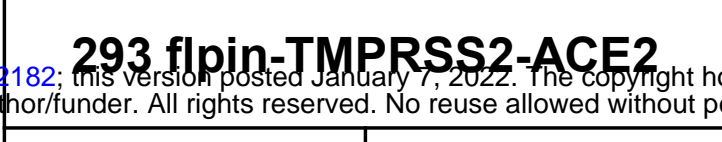 } & \multicolumn{2}{|c|}{$\begin{array}{l}\text { dider for this preprint } \\
\text { armission. }\end{array}$} & \multicolumn{2}{|c|}{293 flpin-TMPRSS2-ACE2 } \\
\hline & & IC50 & IC80 & IC50 & IC80 & IC50 & IC80 \\
\hline VRC & 61.1 & $>10$ & $>10$ & $>10$ & $>10$ & ND & ND \\
\hline REGN & REGN10987 & $>10$ & $>10$ & $>10$ & $>10$ & ND & ND \\
\hline BMS & C135 & $>10$ & $>10$ & $>10$ & $>10$ & ND & ND \\
\hline AZD & COV2-2130 & 0.4133 & 2.8686 & 6.5388 & $>10$ & ND & ND \\
\hline Vir & S309 & 0.2844 & 1.7888 & ND & ND & 0.0195 & 0.1305 \\
\hline Eli Lilly & LY-CoV1404 & 0.0018 & 0.0061 & 0.0019 & 0.0088 & ND & ND \\
\hline & & Concentr & $\mathrm{mL})$ & $0.001-0.01$ & $0.01-0.1$ & $0.1-1$ & $>10$ \\
\hline
\end{tabular}

\section{Abbreviations}

*Historic data; IC50 = concentration (ug/mL) inhibiting

maximal activity by $50 \%$; IC $80=$ concentration $(\mathrm{ug} / \mathrm{mL})$

inhibiting maximal activity by $80 \%$; ND = no data; SARS-

CoV-2 = severe acute respiratory syndrome coronavirus

2. 
Table 3D. Neutralization Activity of Clinically-Relevant Monoclonal Antibodies Against the SARS-CoV-2 variants B.1.1.529 and D614G

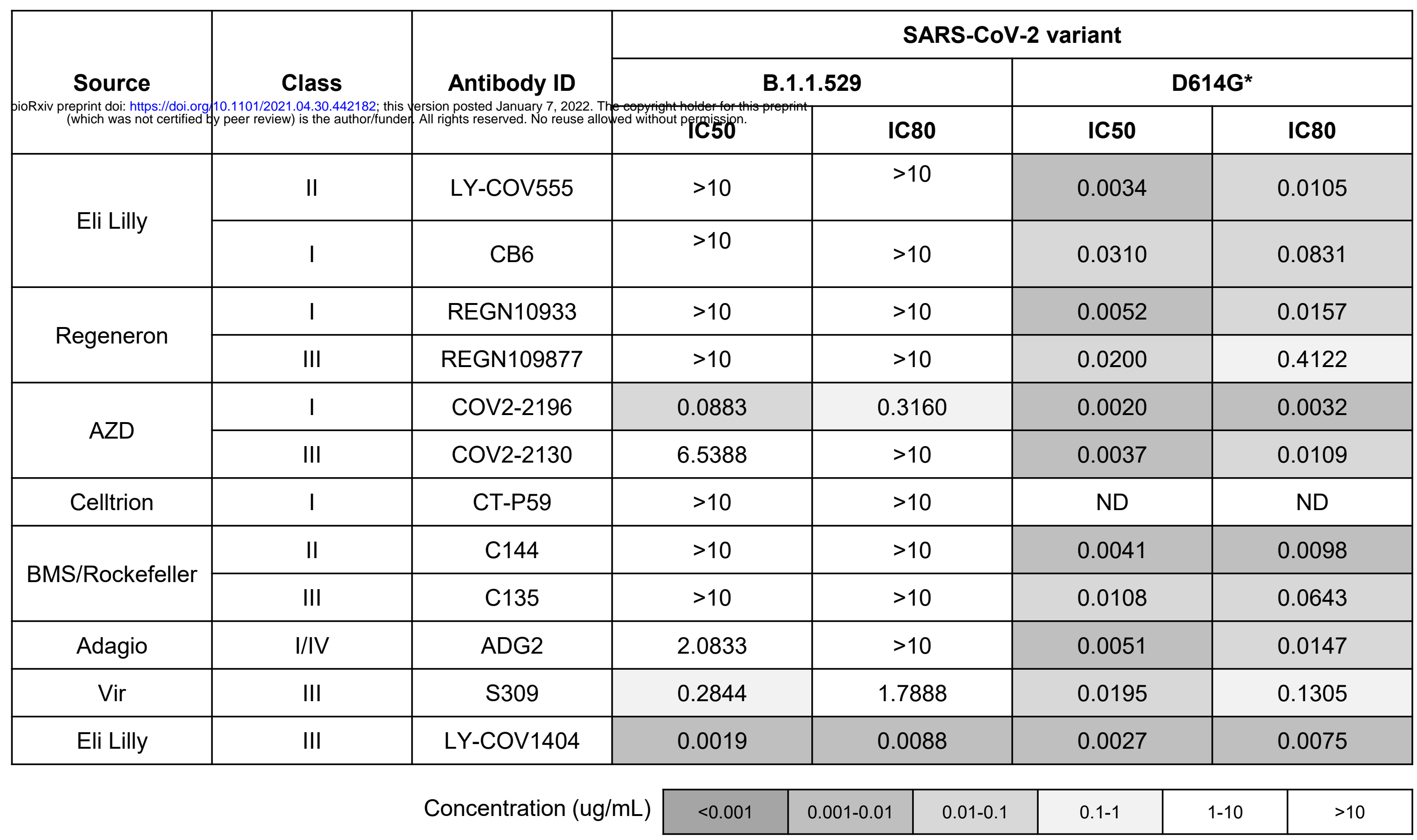

Abbreviations

*Historic data; IC50 = concentration (ug/mL) inhibiting

maximal activity by $50 \%$; IC80 = concentration (ug/mL)

inhibiting maximal activity by $80 \%$; ND = no data; SARS-

CoV-2 = severe acute respiratory syndrome coronavirus

2. 
Table 3D (Continued). Neutralization Activity of Clinically-Relevant Monoclonal Antibodies Against the SARS-CoV-2 variants B.1.1.529 and D614G

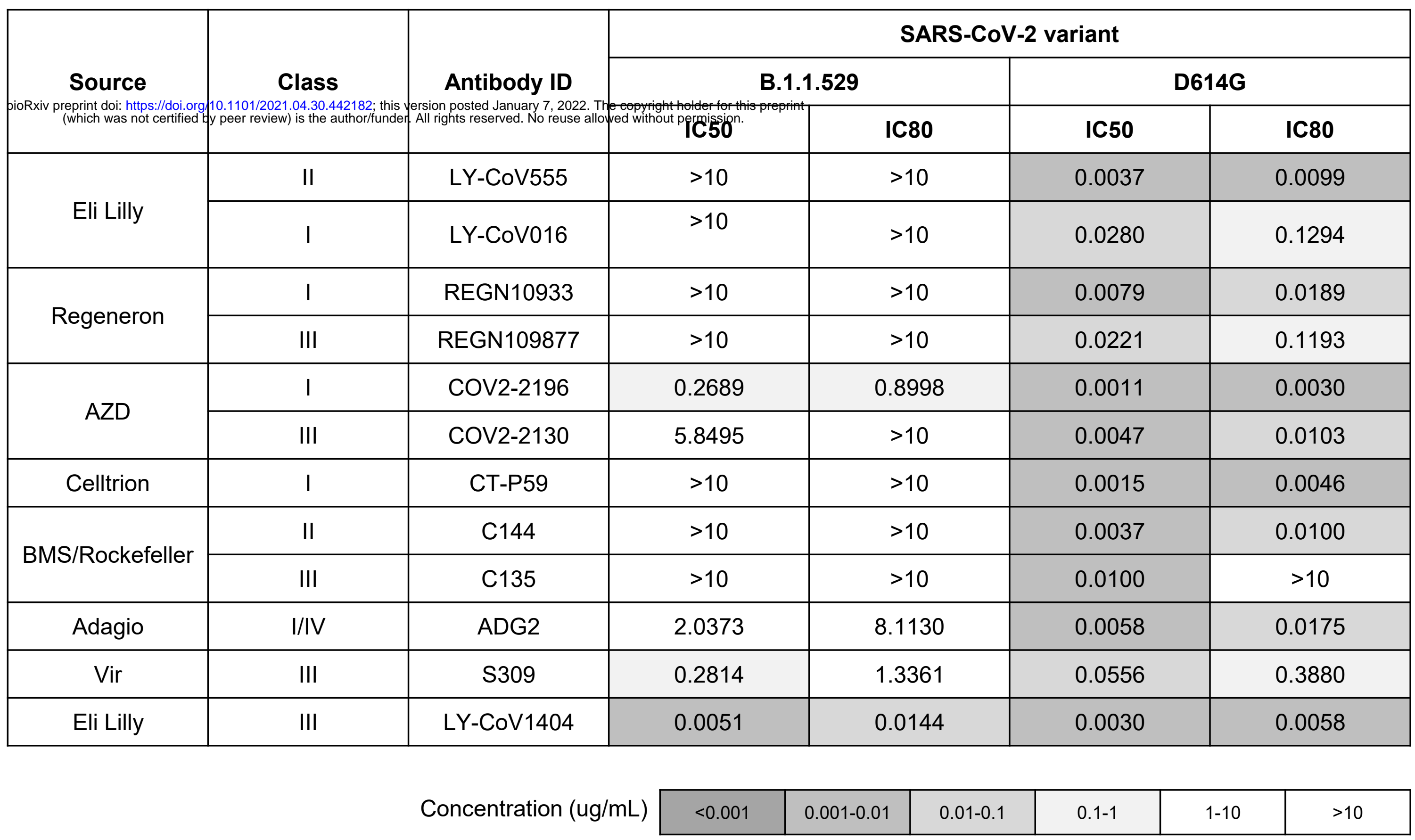

Abbreviations

IC50 = concentration $(\mathrm{ug} / \mathrm{mL})$ inhibiting maximal activity

by $50 \%$; IC $80=$ concentration $(\mathrm{ug} / \mathrm{mL})$ inhibiting maximal

activity by $80 \%$; ND = no data; SARS-CoV-2 = severe

acute respiratory syndrome coronavirus 2 . 
Fig 2A. Live Virus WT IFA LY-CoV555 vs LY-CoV1404 Fig 2B. Live Virus WT IFA LY-CoV555 vs VIR-S309
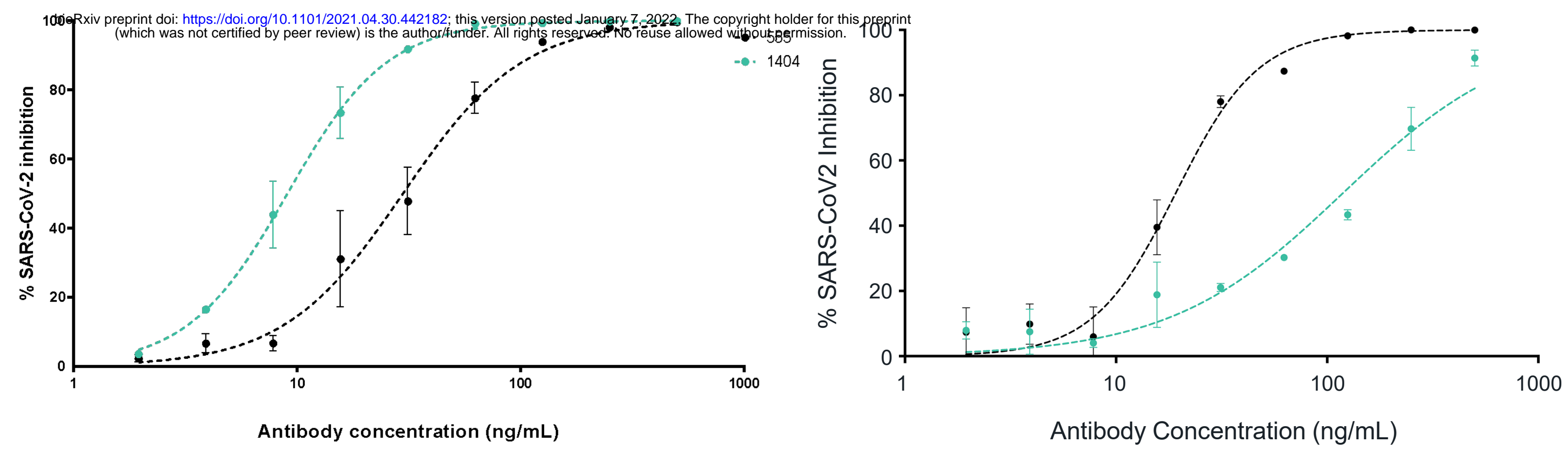

\begin{tabular}{lll}
\hline & IC50s $(\mathbf{n g} / \mathrm{mL})$ & IC90s $(\mathbf{n g} / \mathrm{mL})$ \\
\hline LY-COV1404 & 9.034 & 54.87 \\
LY-CoV555 & $\bullet 29.68$ & 126.48 \\
\hline
\end{tabular}

\begin{tabular}{lll}
\hline & IC50s $(\mathbf{n g} / \mathbf{m L})$ & IC90s $(\mathbf{n g} / \mathbf{m L})$ \\
\hline VIR-S309 & 118.80 & 946.01 \\
LY-CoV555 & $\bullet 19.17$ & 51.65 \\
\hline
\end{tabular}

Fig 2C. IC50 Live Virus Neutralization

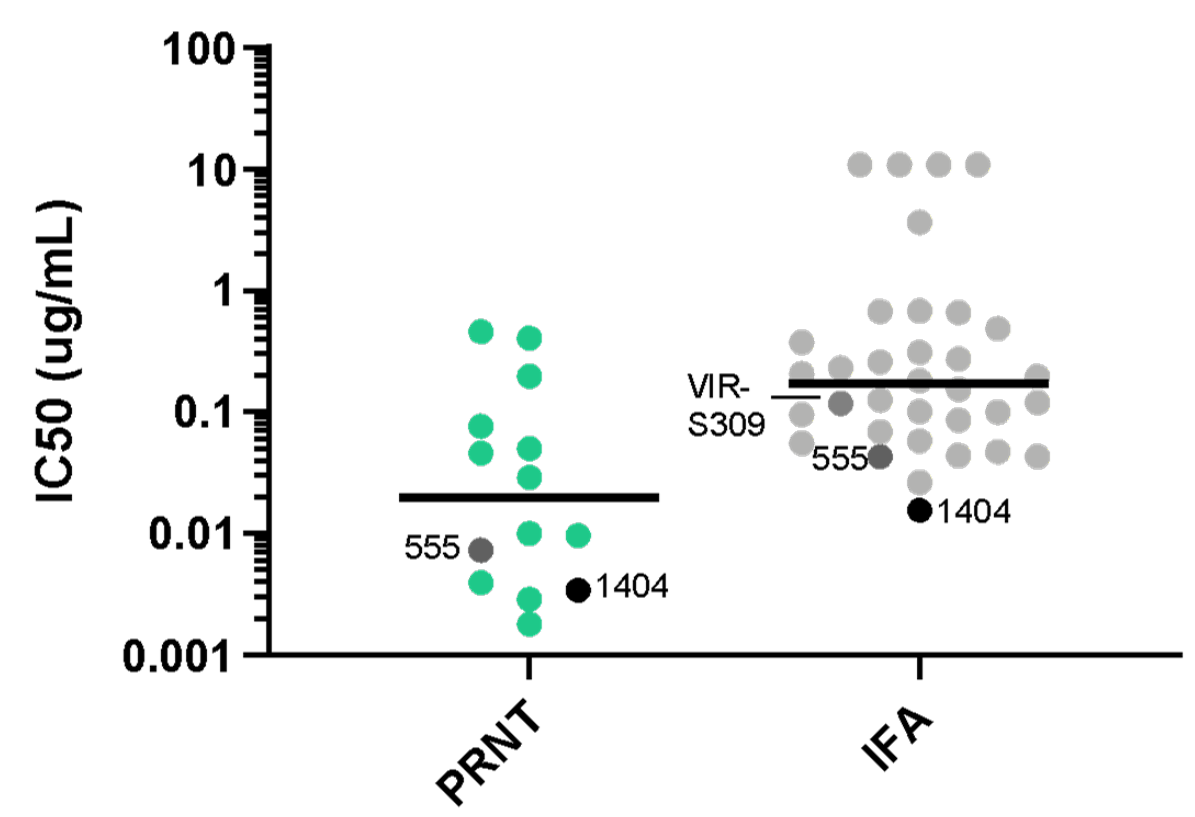


Fig 3. LY-CoV1404 Binds to the Spike Protein RBD and Blocks ACE2 Interactions

A
B

Spike protein RBD
LY-CoV1404
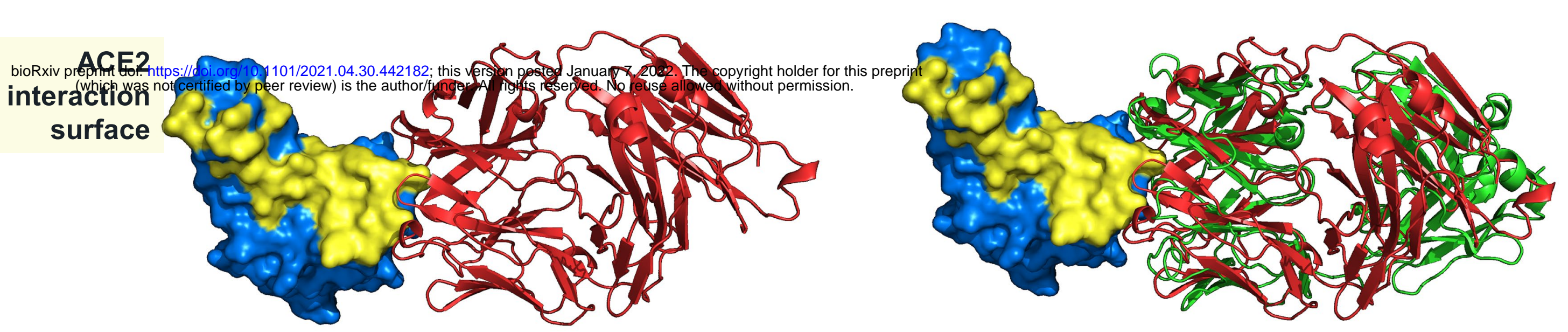

REGN10987
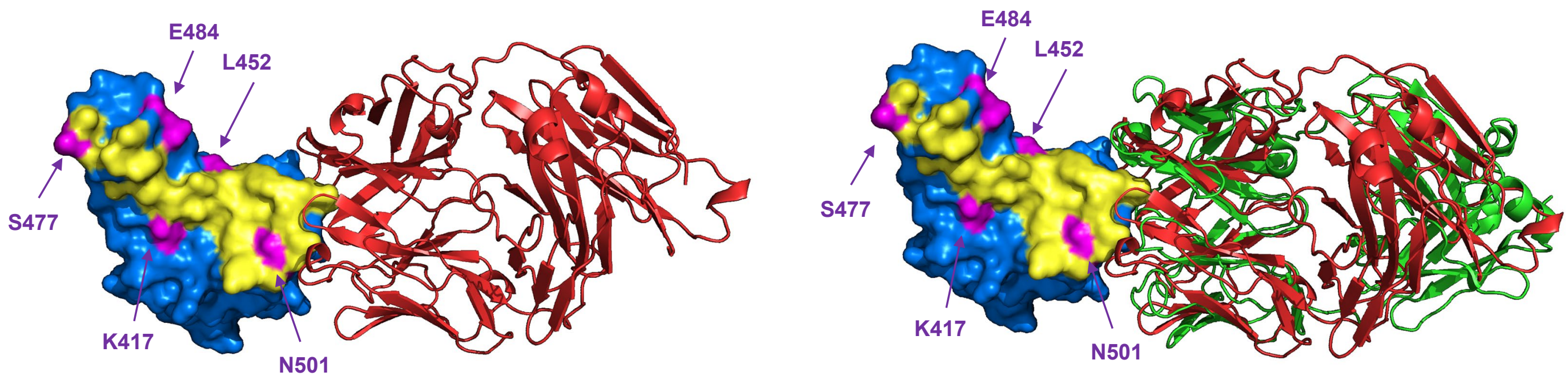
Fig 3. LY-CoV1404 Binds to the Spike Protein RBD and Blocks ACE2 Interactions (continued)

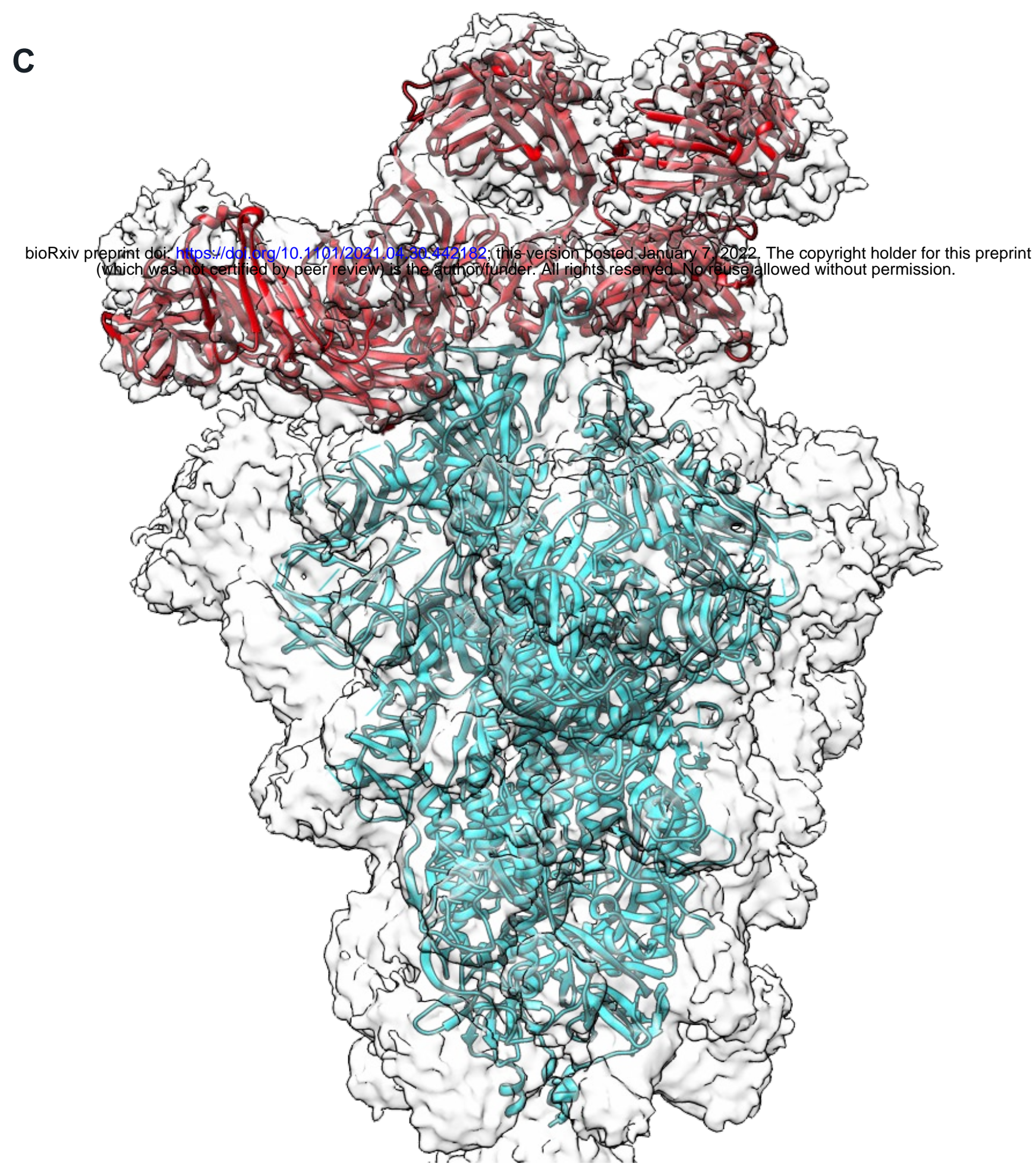


Table 4. Summary of LY-CoV1404-Binding Epitope Positions and their Conservation in GISAID (as of 12/21/20201)

bioRxiv preprint doi: https://doi.org/10.1101/2021.04.30.442182; this version posted danuary 7, 2022. The copyright holder for this prep (which was not certified by peer review) is the author/funder. All rights reserved. No reuse allowed without permission.

RBD Contact Residue

\% Conservation in GISAIDa

\begin{tabular}{ll}
\hline T345 & 99.988 \\
\hline N436 & 99.652 \\
N440 & 97.371 \\
L441 & 99.742 \\
S443 & 99.992 \\
K444 & 99.999 \\
V445 & 99.964 \\
G446 & 99.986 \\
G447 & 99.744 \\
N448 & 99.997 \\
Y449 & 99.996 \\
N450 & 99.955 \\
Q498 & 99.968 \\
P499 & 99.740 \\
T500 & 99.979 \\
N501 & 99.997 \\
G502 & 78.189 \\
V503 & 99.999 \\
Q506 & 99.977 \\
R509 & 99.999 \\
\hline & 99.999 \\
\hline
\end{tabular}

Abbreviations

GISAID = Global Initiative on Sharing All Influenza Data; RBD = receptor binding domain

a \% Conservation is defined as the percentage of deposited sequences containing the nonmutated amino acid in GISAID (as of February 2021). 
Table 5. LY-CoV1404 Activity Against SARS-CoV-2 Variant Proteins and Viruses Located in the LY-CoV1404-Binding Site

\begin{tabular}{|c|c|c|c|c|c|c|c|}
\hline \multirow[b]{2}{*}{$\begin{array}{r}\text { bioRxiv preprint doi: } \\
\text { (which wa }\end{array}$} & \multirow[b]{2}{*}{ 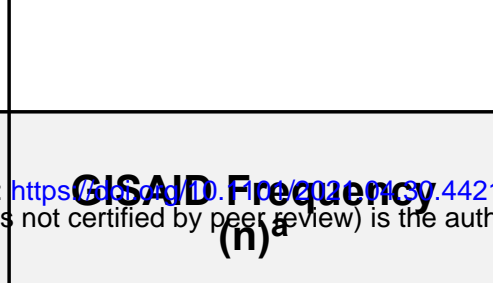 } & \multicolumn{2}{|c|}{ Pseudovirus Susceptibility } & \multicolumn{2}{|c|}{ ACE2-Binding Inhibition } & \multicolumn{2}{|c|}{ SPR Binding } \\
\hline & & 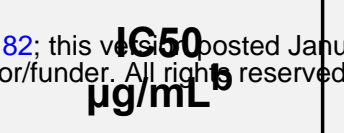 & 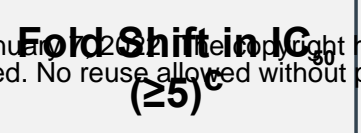 & $\begin{array}{l}\text { holder for th€50 } \\
\text { permissiont } \\
\mathbf{M g} / \mathbf{m L}^{\mathbf{d}}\end{array}$ & $\begin{array}{l}\text { Fold Shift in } \mathrm{IC}_{50} \\
\qquad(\geq 5)^{\mathrm{C}}\end{array}$ & $\begin{array}{l}\text { Binding Affinity } \\
\left(\mathrm{K}_{\mathrm{D}}\right) \text {, at } 25^{\circ} \mathrm{C}\end{array}$ & $\begin{array}{c}\text { Fold Change } \\
\qquad(\geq 5)\end{array}$ \\
\hline Wuhane & & 0.003 & NA & 0.053 & NA & $3.71 \mathrm{nM}$ & NA \\
\hline R346K & $0.00002 \%(1)$ & 0.002 & $\mathrm{nc}$ & & & & \\
\hline N439K & $0.6272 \%(39428)$ & 0.002 & $\mathrm{nc}$ & 0.05 & $\mathrm{nc}$ & $5.05 \mathrm{nM}$ & nc \\
\hline N440D & $0.0005 \%(30)$ & 0.006 & $\mathrm{nc}$ & 0.051 & $\mathrm{nc}$ & - & - \\
\hline N440K & $0.00002(1)$ & 0.001 & nc & & & & \\
\hline $\mathrm{K} 444 \mathrm{Q}$ & & $>0.25$ & $>20$ & 0.777 & 17.5 & $>300^{f} \mathrm{nM}$ & $>81$ \\
\hline V445A & $0.0057 \%(357)$ & $>0.25$ & $>20$ & 0.752 & 17 & $>300^{f} \mathrm{nM}$ & $>81$ \\
\hline G446S & $0.0806 \%(5066)$ & 0.006 & nc & & & & \\
\hline G446V & $0.1683 \%(10580)$ & 0.006 & nc & 0.185 & $n c^{g}$ & $>300^{f} \mathrm{nM}$ & $>81$ \\
\hline $\mathrm{N} 450 \mathrm{~K}$ & $0.0296 \%(1862)$ & 0.002 & nc & & & & \\
\hline Q498R & $0.2580 \%(16218)$ & 0.002 & $\mathrm{nc}$ & & & & \\
\hline P499R & $0.0 .0084 \%(526)$ & $>0.25$ & $>20$ & & & & \\
\hline P499S & $0.0047 \%(296)$ & $>0.25$ & $>20$ & & & & \\
\hline N501Y & $21.7183 \%$ (1365349) & 0.002 & nc & 0.046 & $\mathrm{nc}$ & $2.90 \mathrm{nM}$ & nc \\
\hline
\end{tabular}

\section{Abbreviations}

GISAID = Global Initiative on Sharing All Influenza Data; IC50 = concentration inhibiting maximal activity by $50 \%$; $\mathbf{n}=$ number $; \mathbf{N A}=$ not applicable; $\mathbf{n c}=$ no change (difference was less than $\leq 5$-fold); SARS-CoV-2 = severe acute respiratory syndrome coronavirus 2 .
Frequency was determined from 2,293,883 total number of spike sequences as of 14 July 2021.

b IC50 values presented are geometric mean if multiple experiments were performed and a weighted geometric mean for the Wuhan strain.

c Fold shifts are calculated comparing to the in-experiment Wuhan control. The geometric mean of the fold changes is provided if multiple experiments were performed.

d inhibition of WT RBD sequence is presented as the consensus estimate as of 14 March 2021 achieved across repeat experiments. IC50 for ACE2 binding

e SARS-CoV-2 S GenBank MN908947.3.

$f$ Indicates that while binding was observed, kinetic data were not suitable for fitting. In these cases, a minimum binding affinity was set at the highest Fab concentration used in the experiment. 
Table 6. LY-CoV1404 Activity against SARS-CoV-2 Variant Viruses with Known Resistance to Other Clinical Monoclonal Antibodies

\begin{tabular}{|c|c|c|c|c|c|c|c|}
\hline \multirow{2}{*}{$\begin{array}{l}\text { Spike Protein } \\
\text { Variant }\end{array}$} & \multirow{2}{*}{$\begin{array}{l}\text { mAb with } \\
\text { Reduced Activity }\end{array}$} & \multicolumn{2}{|c|}{ Pseudovirus Susceptibility } & \multicolumn{2}{|c|}{ ACE2-Binding Inhibition } & \multicolumn{2}{|c|}{ SPR Binding } \\
\hline & & $\begin{array}{c}\mathrm{IC} 50 \\
\mu \mathrm{g} / \mathrm{mL}^{\mathrm{a}}\end{array}$ & $\begin{array}{l}\text { Fold Shift in } \\
\text { IC }_{50}(\geq 5)^{\mathrm{b}}\end{array}$ & $\begin{array}{c}\mathrm{IC} 50 \\
\mu \mathrm{g} / \mathrm{mL}^{\mathrm{a}}\end{array}$ & $\begin{array}{l}\text { Fold Shift in } \\
\text { IC }_{50}(\geq 5)^{b}\end{array}$ & $\begin{array}{l}\text { Binding Affinity }\left(\mathrm{K}_{\mathrm{D}}\right) \text {, } \\
\text { at } 25^{\circ} \mathrm{C}\end{array}$ & $\begin{array}{l}\text { Fold Change } \\
\qquad(\geq 5)^{b}\end{array}$ \\
\hline Wuhanc & & 0.003 & NA & 0.053 & NA & $3.71 \mathrm{nM}$ & NA \\
\hline K417E & casirivimab & 0.004 & nc & 0.047 & $\mathrm{nc}$ & $2.59 \mathrm{nM}$ & nc \\
\hline $\begin{array}{l}\text { v preprint doi: https://c } \\
\text { (whik4 Wa9 not cel }\end{array}$ & $\begin{array}{l}\text { oi.org/10.1101/2021.04.30.442182; this } \\
\text { tified by peeptesevewilstiths author/funde }\end{array}$ & $\begin{array}{l}\text { version posted } J \\
\text {. All right.togeser }\end{array}$ & $\begin{array}{l}y 7,2022 \text {. The copyric } \\
\text { Jo reuse âlewed with }\end{array}$ & $\begin{array}{l}\text { holder for this preprint } \\
\text { permissiø?.089 }\end{array}$ & nc & $3.08 \mathrm{nM}$ & $\mathrm{nc}$ \\
\hline K417T & etesevimab & 0.002 & nc & 0.078 & $\mathrm{nc}$ & $2.54 \mathrm{nM}$ & nc \\
\hline D420N & etesevimab & 0.002 & $\mathrm{nc}$ & 0.069 & $\mathrm{nc}$ & $4.09 \mathrm{nM}$ & $\mathrm{nc}$ \\
\hline N440D & imdevimab & 0.005 & $\mathrm{nc}$ & 0.051 & $\mathrm{nc}$ & - & - \\
\hline K444Q & imdevimab & $>0.25$ & $>20$ & 0.777 & 17.5 & $>300$ e $n M$ & $>90$ \\
\hline V445A & imdevimab & $>0.25$ & $>20$ & 0.752 & 17 & $>300$ e nM & $>20$ \\
\hline G446V & imdevimab & 0.013 & $\mathrm{nc}$ & 0.185 & $\mathrm{nc}$ & $>300 \mathrm{e} n M$ & $>81$ \\
\hline L452R & bamlanivimab & 0.002 & $\mathrm{nc}$ & 0.119 & $\mathrm{nc}$ & $4.94 \mathrm{nM}$ & $\mathrm{nc}$ \\
\hline Y453F & casirivimab & 0.002 & $\mathrm{nc}$ & - & - & $3.28 \mathrm{nM}$ & nc \\
\hline N460K & etesevimab & 0.004 & $\mathrm{nc}$ & 0.083 & $\mathrm{nc}$ & $3.40 \mathrm{nM}$ & $\mathrm{nc}$ \\
\hline N460S & etesevimab & 0.002 & $\mathrm{nc}$ & 0.064 & $\mathrm{nc}$ & $2.60 \mathrm{nM}$ & $\mathrm{nc}$ \\
\hline N460T & etesevimab & - & - & 0.102 & $\mathrm{nc}$ & 3.52 nM & nc \\
\hline G476S & casirivimab & 0.005 & $\mathrm{nc}$ & 0.07 & $\mathrm{nc}$ & $4.35 \mathrm{nM}$ & $\mathrm{nc}$ \\
\hline S477N & GISAID & 0.005 & $\mathrm{nc}$ & 0.066 & $\mathrm{nc}$ & $3.45 \mathrm{nM}$ & $\mathrm{nc}$ \\
\hline V483A & bamlanivimab & 0.001 & $\mathrm{nc}$ & 0.074 & $\mathrm{nc}$ & $3.29 \mathrm{nM}$ & $\mathrm{nc}$ \\
\hline E484D & bamlanivimab & 0.003 & $\mathrm{nc}$ & 0.048 & $\mathrm{nc}$ & $3.37 \mathrm{nM}$ & nc \\
\hline E484K & bamlanivimab & 0.002 & $\mathrm{nc}$ & 0.091 & $\mathrm{nc}$ & $3.19 \mathrm{nM}$ & nc \\
\hline E484Q & bamlanivimab & 0.002 & $\mathrm{nc}$ & 0.07 & $\mathrm{nc}$ & $3.74 \mathrm{nM}$ & nc \\
\hline F486I & casirivimab & 0.005 & $\mathrm{nc}$ & 0.06 & $\mathrm{nc}$ & $2.69 \mathrm{nM}$ & nc \\
\hline F486V & $\begin{array}{c}\text { casirivimab, bamlanivimab, } \\
\text { etesevimab }\end{array}$ & 0.003 & $\mathrm{nc}$ & 0.046 & $\mathrm{nc}$ & $2.82 \mathrm{nM}$ & nc \\
\hline Y489H & casirivimab & 0.006 & $\mathrm{nc}$ & 0.037 & $\mathrm{nc}$ & $3.06 \mathrm{nM}$ & $\mathrm{nc}$ \\
\hline F490S & bamlanivimab & 0.006 & $\mathrm{nc}$ & 0.112 & $\mathrm{nc}$ & $2.99 \mathrm{nM}$ & nc \\
\hline Q493K & $\begin{array}{c}\text { casirivimab, bamlanivimab, } \\
\text { etesevimab }\end{array}$ & 0.003 & $\mathrm{nc}$ & 0.09 & $\mathrm{nc}$ & $2.72 \mathrm{nM}$ & nc \\
\hline Q493R & bamlanivimab, etesevimab & 0.002 & $\mathrm{nc}$ & 0.063 & $\mathrm{nc}$ & $3.51 \mathrm{nM}$ & $\mathrm{nc}$ \\
\hline S494P & bamlanivimab & 0.001 & $\mathrm{nc}$ & 0.067 & $\mathrm{nc}$ & $3.46 \mathrm{nM}$ & nc \\
\hline
\end{tabular}

\section{Abbreviations}

- = not tested; ACE2 = angiotensin-converting enzyme 2; $\mathbf{C l}=$ confidence interval; del= deletion; GISAID = Global Initiative on Sharing All Influenza Data; IC50 = concentration inhibiting maximal activity by $50 \% ; \mathrm{mAb}=$ monoclonal antibody; $\mathbf{n c}=$ no change (difference was less than $\leq 5$-fold); $\mathbf{N A}=$ not applicable; SARS-CoV-2 = severe acute respiratory syndrome coronavirus 2. a IC50 values presented are geometric mean if multiple experiments were performed and a weighted geometric mean for the Wuhan strain $(n=10) 95 \% \mathrm{Cl}$ values were included for variants tested only once. IC50 for ACE2-binding inhibition of Wuhan sequence is presented as the consensus estimate as of 26 February 2021 achieved across repeat experiments.

b Fold shifts are calculated comparing to the in-experiment Wuhan control. The geometric mean of the fold changes is provided if multiple experiments were performed. For ACE2-binding inhibition, no inhibition represents $<50 \%$ ACE2-binding inhibition with up to $3.75 \mu \mathrm{g} / \mathrm{mL} \mathrm{mAb}$.

c SARS-CoV-2 S GenBank MN908947.3. 


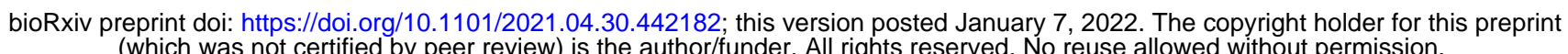
(which was not certified by peer review) is the author/funder. All rights reserved. No reuse allowed without permission.

\section{SUPPLEMENTARY FIGURES}




\section{Fig S1. ACE2 Competition}
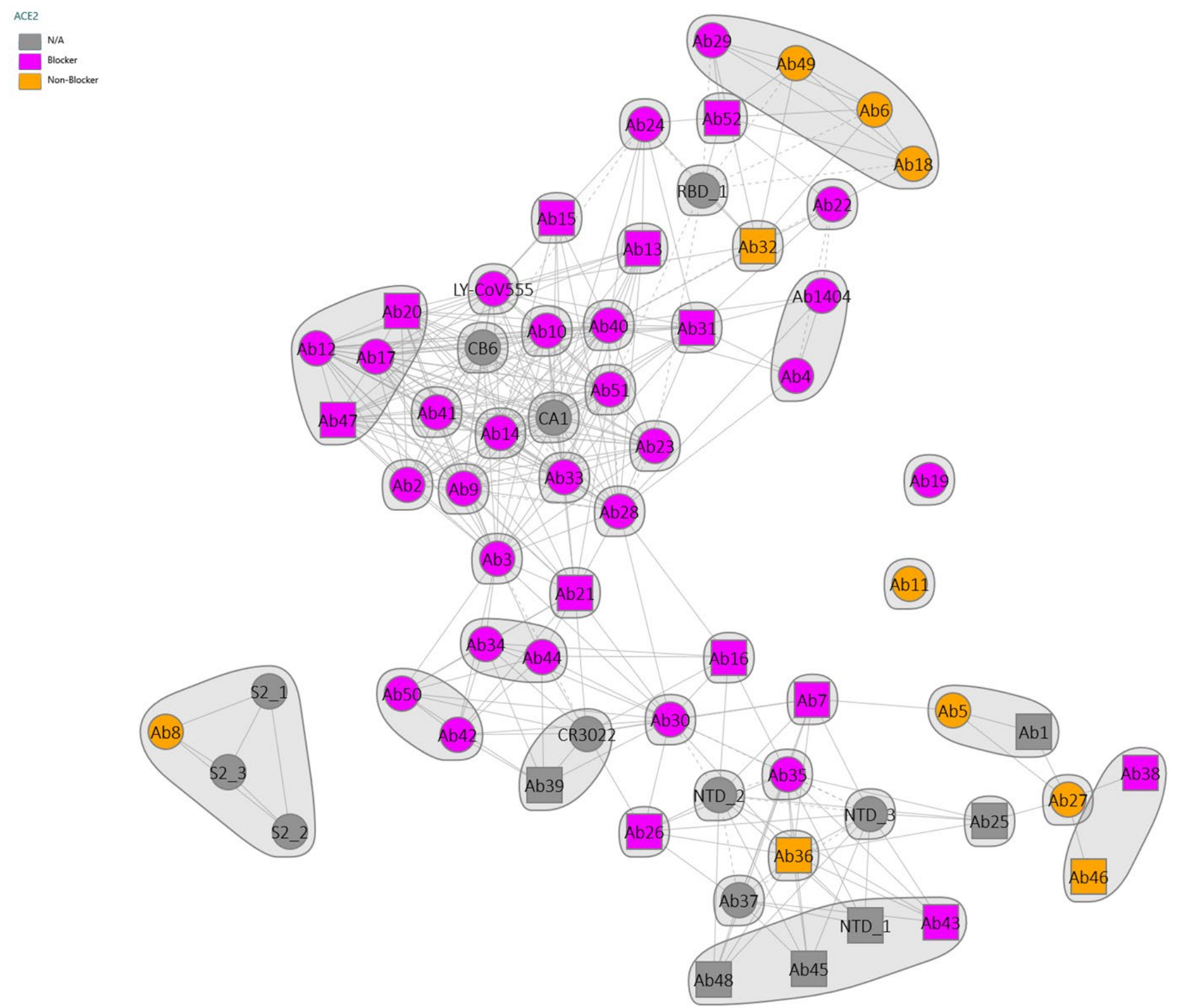
Fig S2. LY-CoV1404 binding to trimeric S protein

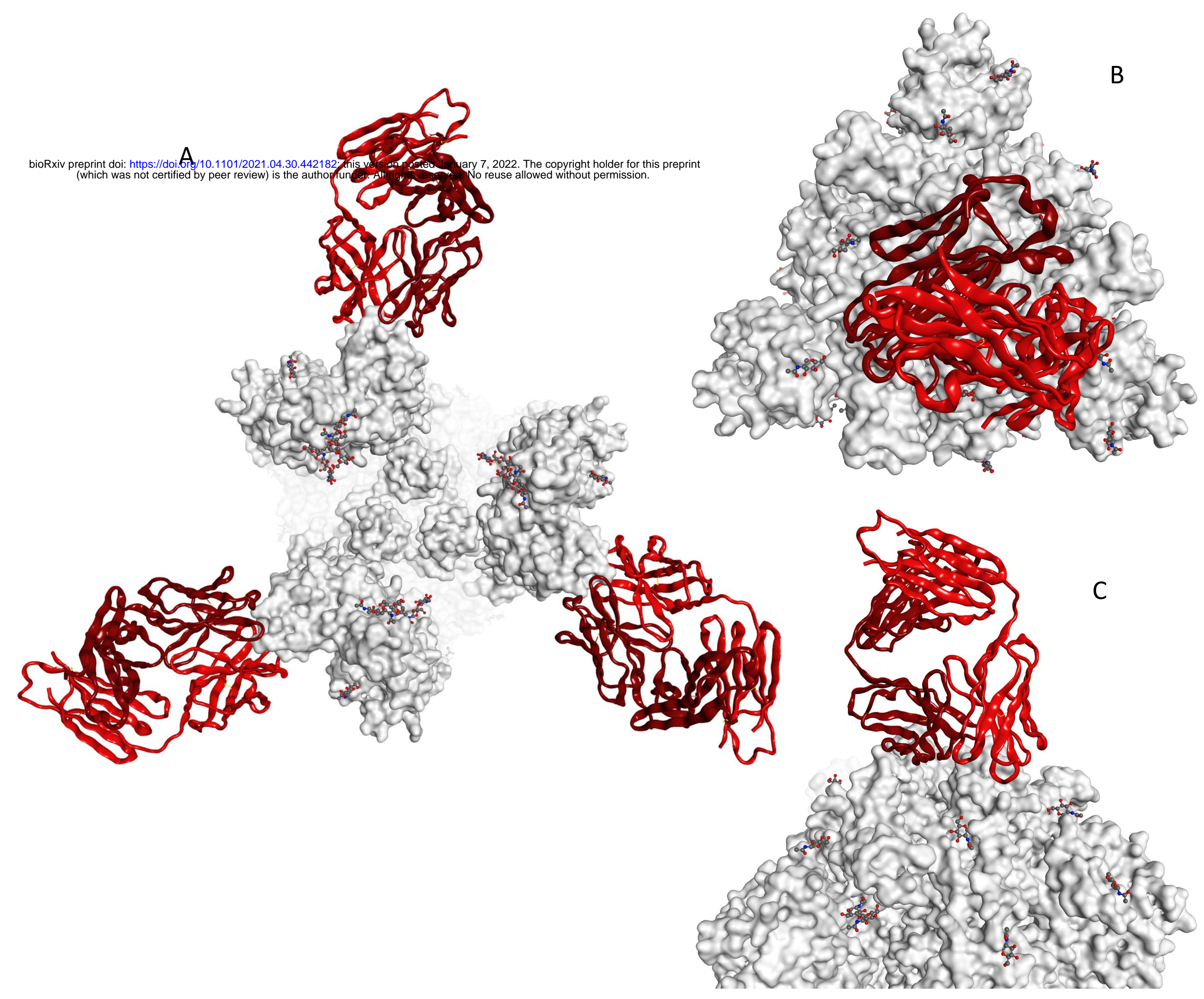


Fig S3. Antibody binding to variant B.1.351 and antibody epitopes.

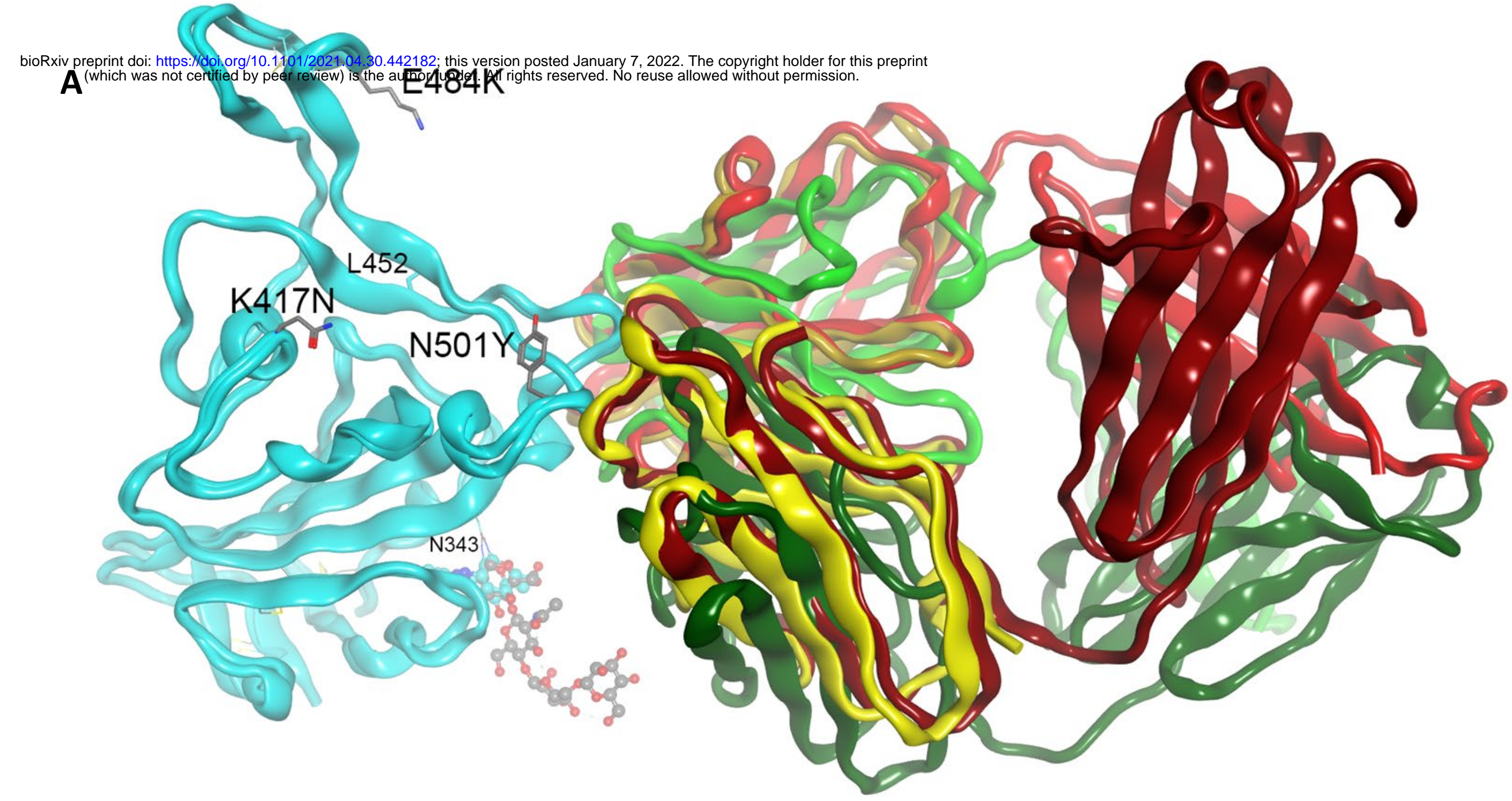

B

author antibody PDB FPNITNLCPFGEVFNATRFAS ... CVIAWNSNNLDSKVGGNYNYLYRLFRKS

\begin{tabular}{|c|c|c|}
\hline ABCL/LLY & 1404 & \\
\hline Hansen... & REGN10987 & $6 x d g$ \\
\hline Cerutti... & Fab2-7 & 7 7lss \\
\hline Wang... & ACE2 & $6 \mathrm{m0j}$ \\
\hline Yan... & ACE2 & $6 \mathrm{~m} 17$ \\
\hline
\end{tabular}
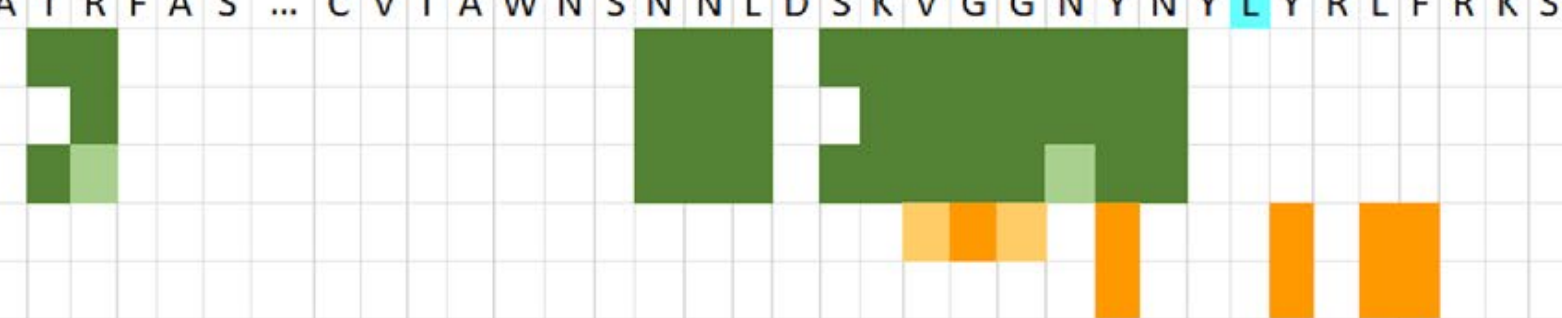

460

480

490

500

510

NLKPFERDISTEIYQAGSTPCNGVEGFN CYFPLQSYGFQPTNGVGYQPYRVV

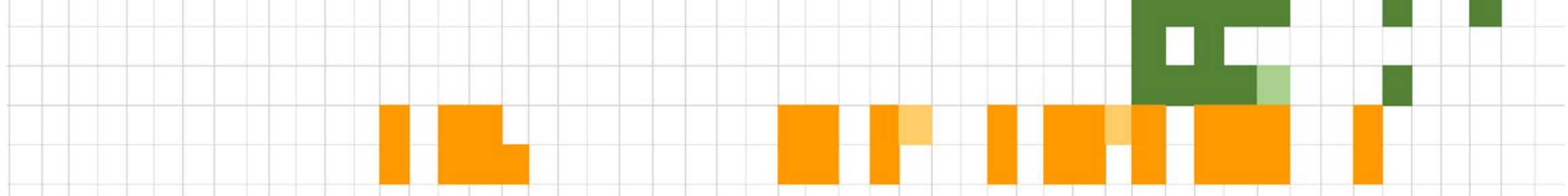


bioRxiv preprint doi: https://doi.org/10.1101/2021.04.30.442182; this version posted January 7, 2022. The copyright holder for this preprint (which was not certified by peer review) is the author/funder. All rights reserved. No reuse allowed without permission.

Table S1. Crystallographic statistics

\begin{tabular}{|c|c|}
\hline & LY-CoV1404 + spike protein RBD \\
\hline \multicolumn{2}{|l|}{ Data collection } \\
\hline Space group & P2(1)2(1)2(1) \\
\hline $\begin{array}{l}\text { Cell dimensions } \\
\text { a, b, c }(\AA)\end{array}$ & $73.09,107.69,190.47$ \\
\hline $\begin{array}{l}\text { Cell dimensions } \\
\text { alpha, beta, gamma }\left(^{\circ}\right)\end{array}$ & $90,90,90$ \\
\hline Resolution $(\AA)$ & $\begin{array}{l}94-2.43 \\
(2.57-2.43)^{*}\end{array}$ \\
\hline R-merge & $0.069(0.690)$ \\
\hline $\mathrm{I} / \operatorname{sigma}(\mathrm{I})$ & $15.0(2.5)$ \\
\hline Completeness (\%) & $99.8(99.9)$ \\
\hline Redundancy & $6.4(6.8)$ \\
\hline \multicolumn{2}{|l|}{ Refinement } \\
\hline Resolution $(\AA)$ & $94-2.43$ \\
\hline No. of reflections & 57431 \\
\hline R-work (\%) / R-free (\%) & $23.5 / 26.4$ \\
\hline $\begin{array}{l}\text { No. of non-hydrogen atoms } \\
\text { protein / ligand / water }\end{array}$ & $9236 / 14 / 73$ \\
\hline $\begin{array}{l}\text { B-factors } \\
\text { protein / ligand / water }\end{array}$ & $60.2 / 72.8 / 44.8$ \\
\hline $\begin{array}{l}\text { Root mean squared deviations } \\
\text { bond length }(\AA) / \\
\text { bond angle }\left(^{\circ}\right)\end{array}$ & $0.011 / 1.63$ \\
\hline $\begin{array}{l}\text { Ramachandran distribution } \\
\text { phi-psi favored (\%)/ } \\
\text { phi-psi allowed (\%) }\end{array}$ & $97.0 / 99.8$ \\
\hline
\end{tabular}

\section{*Values in parenthesis denote highest resolution shell}


Table S2. Summary of atomic interactions at the RBD epitope.

bioRxiv preprint doi: https://doi.org/10.1101/2021.04.30.442182; this version posted January 7, 2022. The copyright holder for this preprint (which was not certified by peer review) is the author/funder. All rights reserved. No reuse allowed without permission.

\begin{tabular}{|lcccc|}
\hline Antibody & PDB ID & $\begin{array}{c}\text { atom-atom } \\
\text { contacts }\end{array}$ & H-bonds & $\begin{array}{c}\text { RBD contact } \\
\text { surface area } \AA^{2}\end{array}$ \\
\hline LY-CoV1404 & 7MMO & 198 & 12 & 584 \\
\hline REGN10987 & 6XDG & 70 & 6 & 343 \\
\hline Fab 2-7 & 7LSS & 156 & 10 & 496 \\
\hline
\end{tabular}


Fig 3. LY-CoV1404 Binds to the Spike Protein RBD and Blocks ACE2 Interactions

A

\section{Spike protein RBD}

LY-CoV1404

ACE2

interaction surface

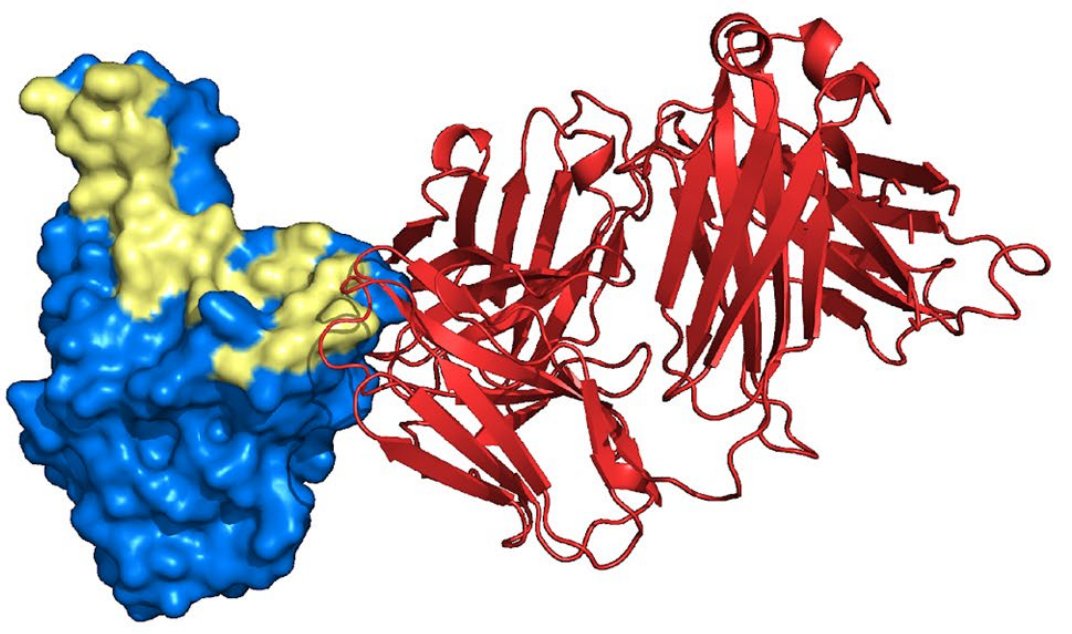

B

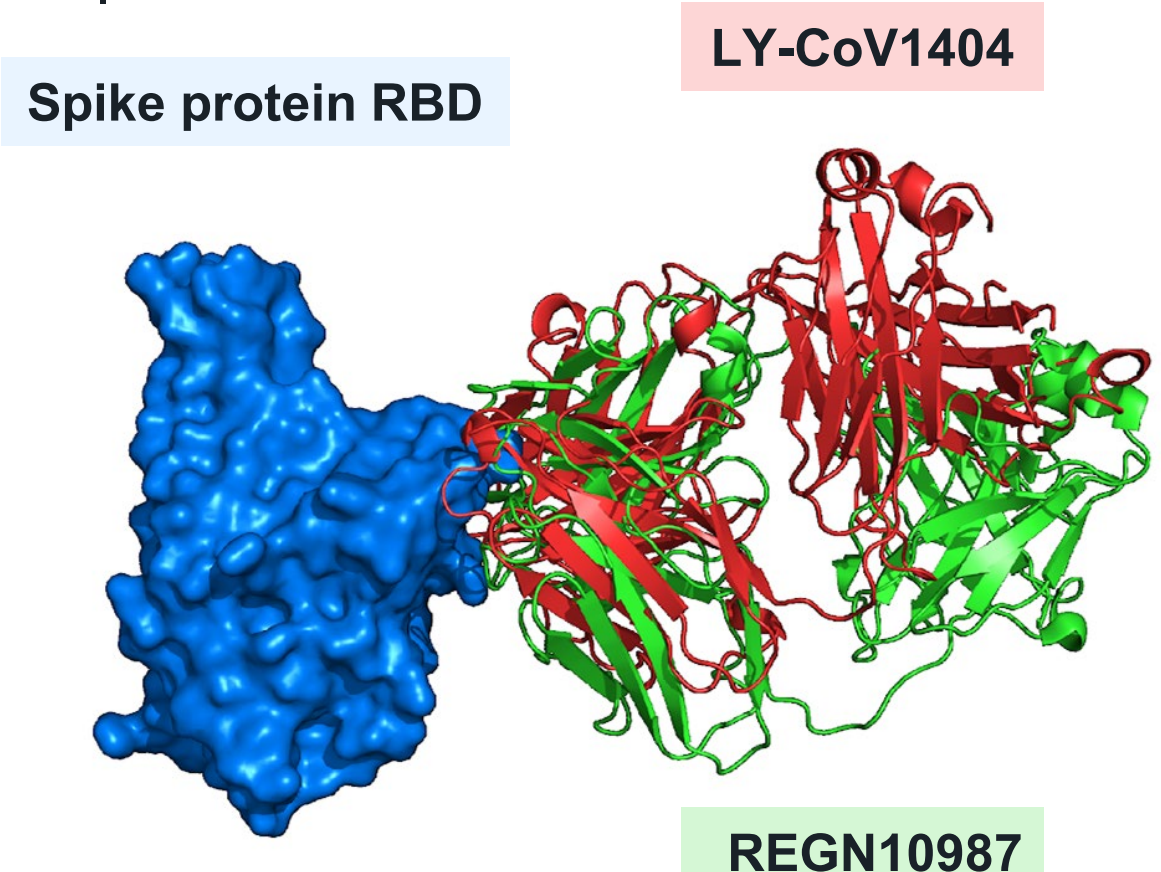

